\title{
Política, gramática y enseñanza del español en los últimos años de la Nueva España y principios del México independiente: una aproximación desde la prensa periódica
}

\author{
Manuel Rivas Zancarrón ${ }^{1}$ \\ Universidad de Cádiz, España
}

\begin{abstract}
Resumen
Después de la Independencia mexicana, el nuevo orden social requería también discutir sobre la deriva que tomaría la lengua de sus nuevos ciudadanos, una de las pocas herencias a la que no se estaba dispuesto a renunciar. Para ello, los poderes legislativos deberían hablar sobre cómo designarían a su instrumento comunicativo y sobre cómo debía este enseñarse en las escuelas. Las discusiones en torno a la lengua y su deriva política fue objeto de polémica en los primeros años de la Independencia, la cual quedó plenamente reflejada en los periódicos mexicanos. Este estudio pretende dar cuenta de las primeras discusiones en torno a la lengua y su enseñanza en los principales medios de opinión pública mexicanos de las primeras décadas del siglo XIX, así como ofrecer un panorama de los antecedentes de esta situación a partir de los inicios de la prensa de la Nueva España en el siglo XvIII.
\end{abstract}

\footnotetext{
1 Para correspondencia, dirigirse a: Manuel Rivas Zancarrón (manuel.rivas@uca.es), Facultad de Filosofía y Letras, Área de Lengua Española, Avda. Dr. Gómez Ulla, s/n, 11003, Cádiz, España. ORCID 0000-0002-0450-9344.
} 
Palabras clave: política y planificación lingüísticas, historiografía lingüística, prensa, siglos XVIII y XIX.

Politics, GRAmmar AND TEACHING OF SPANish IN THE LAST YEARS OF 'NuEVA ESPAÑA' AND THE BEGINNINGS OF INDEPENDENT MEXICO: AN APPROACH FROM THE PERIODIC PRESS

Abstract

After Mexican Independence, the new social order also required discussing the drift that the language of its new citizens would take, one of the few inheritances that was not willing to give up. For this, the legislative powers should talk about how they would designate their communication instrument and about how it should be taught in schools. The discussions around the language and its political drift was the subject of controversy in the first years of Independence, which was fully reflected in the Mexican newspapers. This study aims to account for the main discussions around the language and its teaching in the main Mexican public opinion media in the first decades of the 19th century, as well as to offer an overview of the antecedents of this situation since the beginning of the press of the Nueva España in the 18th century.

Keywords: Language planning and policy, linguistic historiography, Press, 18th and 19th centuries.

Recibido: 15/01/21 Aceptado: 03/02/21

\section{INTRODUCCIÓN ${ }^{2}$}

Entre los asertos que se le atribuyen a Aristóteles, se encuentra esa casi verdad de perogrullo de que el ser humano se distingue de los animales porque habla. Y más reconocible en sus escritos está ese otro de que, una vez alcanzado el tan ansiado nivel de raciocinio gracias a esa facultad

2 Este trabajo se ha realizado en el marco del proyecto Actitudes lingüisticas e ideas pedagógicas en la prensa española del siglo XIX. Perspectivas sobre la identidad andaluza (ref. P18-RT-3117), concedido en la convocatoria de 2018 del Plan andaluz de investigación, desarrollo e innovación (PAIDI 2020) de la Junta de Andalucía. Modalidad Retos de la sociedad andaluza. 
de comunicación, aquel que se atreve a transmitir mediante la lengua un pensamiento o una idea se convierte casi sin quererlo en un zoón politikón, esto es, en un ente político. Estas dos características indisociables de nuestra naturaleza, que ponen en relación el qué y el cómo de un mensaje, se articulan constantemente en cada actividad o acto verbal (en sentido bühleriano) y se graban en la memoria colectiva gracias al producto de lo emitido -una suerte de érgon humboldtiano, también de reminiscencias aristotélicas--. Cuando el investigador de la lengua quiere acceder al meollo de cómo funciona realmente ese mecanismo que nos convierte en seres racionales, tiene que abstraerse de todo lo que ha posibilitado que se ejerciera un acto de hablar concreto, esto es, del yo, del tú y del momento en el que se ha emitido el mensaje. Las leyes que ponen en marcha el mecano lingüístico deben rescatarse en estado puro, para, así, acceder al tan deseado sistema estructuralista o a las tantas veces aludida estructura profunda del generativismo (innere Sprachform, en Humboldt, Sprachgebilde, en Bühler, langue, en de Saussure, o como quiera llamársele). Sin embargo, las lenguas no solo transmiten, sino que también se transmiten, y lo hacen históricamente, esto es, de generación en generación, de lugares a lugares, de colectivos sociales a colectivos sociales, y a través de un largo etcétera. Siendo esto así, resultaría difícil entender las causas de la mudanza lingüística si no pudiéramos poner en conexión lo que ahora hablamos con ese producto o érgon engrosado con el tiempo a lo largo de la historia. Aquí reside el objetivo principal de este trabajo, esto es, descubrir los motivos por los que la lengua actual que hablamos es resultado de un producto diferente - en cuanto a la variación experimentada- $\mathrm{y}$, al mismo tiempo, igual-respecto de su funcionamiento interno-. Para que este objetivo pueda llegar a buen puerto, habremos de poner en conexión una determinada manifestación lingüística con los agentes que la hicieron posible desde la perspectiva del acto de hablar (tipos de hablante y sus creencias e ideologías ante la lengua; entorno social, económico y político; momento y lugar de emisión; etcétera), y también desde el prisma del producto lingüístico (tipo textual; manifestación escrita; recepción del mensaje y obstáculos en su configuración -dificultades para su impresión y difusión-, etcétera). Y nos serviremos de una fuente documental, los textos periodísticos, de los que reconoceremos y argumentaremos sus bondades a la hora de extraer todas aquellas variables que pudieron incidir en el cambio lingüístico del español en los siglos XVIII y XIX en el espacio geográfico conocido como Nueva España y, posteriormente, México. Los escritos publicados en la prensa periódica, por su carácter de mayor inmediatez, abrirían nuevos caminos para abordar el problema de la variación desde las conciencias y creencias de los hablantes de español, pues la prensa actuaría de canal inmediato en la creación de una opinión pública que contribuiría a moldear una norma 
lingüística. Aquí, lengua, ideología, actitudes y política se unen para decidir cómo deberían hablar y escribir los ciudadanos. La prensa de ese periodo ofrecía muestras explícitas del continuo debate político al que se sometió la lengua, siempre con objeto de crear opinión y conciencia lingüísticas. Por esta razón, hemos querido enfocar este trabajo desde ese estrecho lazo que une la lengua -como instrumento- con el universo creencial e ideológico de sus hablantes, para, de esta manera, tratar de reconstruir desde la ideología y actitudes los procesos de planificación del corpus y del estatus lingüísticos durante los últimos años de la Colonia y los primeros momentos del México independiente. Solo así podremos hacernos una idea más exacta del poder que ejerce el componente ideológico y creencial sobre los procesos de mudanza lingüística en el periodo que estudiamos; o de por qué algunas normas triunfaron en unos territorios y no en otros; o cuáles son los factores que contribuyeron a dar prestigio o a refrendar socialmente una determinada forma de hablar; o por qué unas fronteras nacionales recién creadas reaccionaron de manera diferente con respecto al destino de su instrumento de comunicación. En definitiva, se trataría de arrojar luz sobre el hecho de cómo los espacios de opinión pública pudieron erigirse como caldos de cultivo en el fomento de los procesos de planificación lingüística de un territorio, que llevarían irremediablemente a la intervención de la lengua desde un punto de vista político.

\section{ESTADO DE LA CUESTIÓN TEÓRICA Y METODOLÓGICA}

\subsection{ENCUADRE HISTÓRICO: IDEOLOGÍAS Y POLÍTICAS LINGÜÍSTICAS EN EL MUNDO HISPÁNICO}

\subsubsection{Panorama general hasta el siglo xviii}

Los procesos de planificación y política lingüísticas que pudieron tener lugar hasta el siglo XVIII en España y la América hispana vienen caracterizados por una convivencia fructífera entre el castellano y las lenguas indígenas. A pesar de que con los Reyes Católicos comienza el proceso de expansión del español por América, es más que discutible la idea de que los monarcas pudieran haber planteado alguna política de planificación lingüística, habida cuenta también de la situación que acontecía en los diferentes reinos de España. Es muy posible, como afirma Garza Cuarón (1991), que Isabel y Fernando entendieran "evangelizar" por "castellanizar". Téngase en 
cuenta que cuando los españoles llegaron a América se encontraron con lenguas indígenas potentes y de raíces diversas (maya, zapoteco, tolteco, náhuatl...) y que, entre ellas, podrían haber surgido ya similares propuestas a las de Nebrija para el castellano -transformar este vehículo en lengua de un imperio-, sobre todo en torno al náhuatl, que se erigió en lingua franca para acrecentar la unidad y poder entre los pueblos indígenas. Los españoles contemplaron la necesidad de mantener el náhuatl para, después, proceder a la castellanización, pues era más fácil consumar este último proceso desde una lengua potente y unificada, que desde la diversificación lingüística. De otro lado, el mantenimiento del orden civil y religioso se hacía más cómodo desde la fortaleza de una única lengua indígena, pues los conceptos se tergiversarían con la diversidad de hablas. En un principio, por tanto, en la decisión por una lengua u otra primaba más la labor religiosa de evangelizar, por lo que, viendo una mayor posibilidad de consumar este proceso desde el mantenimiento de las lenguas indígenas, se optó por preservar estas últimas y acercarse al estudio de ellas. No obstante, esta opción de servirse de lo aborigen con un fin religioso no formó parte nunca de los deseos reales de la Corona, que emitió continuas leyes para la castellanización de los indios, dado que, así, podría controlarlos mejor. En 1550, Carlos I quiso poner fin a la cristianización en lenguas vernáculas, pues veía que estas no eran los mejores sistemas de comunicación para la comprensión real de la doctrina cristiana, razón esta que lo llevó a crear escuelas para enseñar castellano. Esta situación cambió en parte durante los reinados de Felipe II, III y IV, en donde se dio vía libre a llevar a cabo la evangelización en castellano y en las otras lenguas habladas en América. Estas leyes, empero, eran desobedecidas casi sistemáticamente por los frailes, a los que les interesaban más la labor de evangelizar que la de castellanizar, pues la primera resultaba más efectiva con el uso de las lenguas aborígenes.

Ciertamente, hubo intentos de enseñar castellano en el seno de los evangelizadores, pues los misioneros tenían que hacer un esfuerzo adicional en la comprensión de las nuevas lenguas, las cuales, en la mayoría de las ocasiones, solo conseguían dominar parcialmente. La insistencia, sin embargo, llevó a un mejor dominio de estas por parte de los doctrineros y a que se estudiaran desde un punto de vista científico.

\subsubsection{Situación desde el siglo XVIII}

La postura política más centralista de los Borbones, frente a la más federalista de los Austria, tuvo, naturalmente, consecuencias en la vertiente lingüística, una nueva actitud que comenzó a cristalizarse con los Decretos de Nueva Planta emitidos por Felipe V entre 1707 y 1716. Aquí se obligaba a usar 
el castellano en todos los escritos de la Audiencia, en sustitución del latín. A pesar de estas políticas más centralizadas en el castellano, el siglo XVIII es especialmente prolijo en el estudio de las lenguas vernáculas $y$, paradójicamente, en la petición por parte de los nobles indígenas de que se enseñara en castellano para un mejor entendimiento de la doctrina cristiana, un ruego que no llegó a oírse hasta 1772, con la apertura de colegios por parte de Carlos III. Y, a pesar de los deseos de esta nobleza indígena, los frailes no estaban por la labor de aceptar sus peticiones de enseñanza del castellano, pues uno de los requisitos para hacerse cargo de una parroquia era hablar una lengua vernácula. De esta manera, conseguían los criollos mantener alejada la posibilidad de que se asentaran en sus territorios sacerdotes procedentes de España que solo hablaban castellano, además de que era más rentable (para fomentar la división de clases) mantener a los indígenas en el desconocimiento de esta lengua, a quienes se les prohibía hablar.

A los clérigos, por otra parte, les interesaba que los indios no hablasen español -al que lo hacía, solían castigarlo-, pues era también una manera de mantener las diferencias sociales. Además, a los curas les interesaba, igualmente, preservar a los indios de las malas costumbres sociales de los españoles.

Con este panorama, señala Tanck de Estrada (1989: 35) que se tomaron, respecto de la educación, varias decisiones político-religiosas que afectaron a la lengua: 1. la secularización de las doctrinas de indios pasó de los frailes locales a los obispos por una orden de Fernando VI en 1749 (los indios tuvieron que aportar dinero para crear escuelas donde se enseñara español, aunque estos se opusieron y ralentizaron el proceso); 2. la expulsión de los jesuitas; 3 . el nombramiento de sacerdotes españoles en vez de criollos en las parroquias indígenas, y 4. la prohibición de usar las lenguas vernáculas. Además, la conquista de nuevos territorios obligaba al descubrimiento de nuevas lenguas y a la multiplicación de los intérpretes, por lo que el Arzobispo de México, Antonio Lorenzana, le solicitó a Carlos III la prohibición de las lenguas prehispánicas, que, además, favorecían el aislamiento de los indios y las consecuentes antipatías hacia los españoles. Ante estos acontecimientos, Carlos III emite la Real Cédula de 1770, en donde se explicita lo siguiente: "Para que en los reynos de las Indias, islas adyacentes y de Filipinas, se pongan en práctica y observen los medios que se refieren y ha propuesto el arzobispo de México, a fin de conseguir que se destierren los diferentes idiomas de que se usa en aquellos dominios, y solo se hable el castellano" (apud Velasco Ceballos 1945: 81). De esta manera, el monarca pensó poner fin a todos los conflictos. No obstante, el virrey Antonio María Bucareli retrasó las medidas por las protestas de los clérigos, a pesar de que a la de 1770, le sucedieron otras Reales Cédulas 
(1774, 1776 y 1778), donde se ratificaba la castellanización, que comenzó a ganar terreno lentamente.

A partir del siglo XIX, y con los procesos de independencia en ciernes (América de España y España de Francia), el español consiguió defenderse del afrancesamiento, por un lado, y de los ataques viscerales de las antiguas colonias, por otro, las cuales prefirieron mantenerlo en favor de una unidad americana, a la que la diversidad y número de lenguas indígenas no podrían contribuir.

\subsection{ENFOQUE METODOLÓGICO}

\subsubsection{Antecedentes metodológicos generales}

El acceso a nuestro objeto de estudio se inscribe dentro de la sociolingüística histórica y contribuiría a ofrecer nuevos apoyos documentales a los procesos políticos de planificación de la norma en territorios concretos de manifestación, así como de las actitudes que se generaron ante la lengua en un espacio social determinado. En este sentido metodológico, es comúnmente aceptado ( $c f$. Moreno Fernández 2008, o Amorós Negre 2008) que fue Einar Haugen (1959: 8), quien comenzara a introducir el término planificación lingüistica para aludir a la "activity of preparing a normative orthography, grammar, and dictionary for the guidance of writers and speakers in a nonhomogeneous speech community", aunque ya Weinrich, en un seminario impartido en la Universidad de Columbia en 1957, había aludido al mismo concepto, cristalizado en un idéntico sintagma. Hasta ese momento, se conocían términos como el de ingeniería lingüistica (Miller 1950) o glotopolítica (Hall 1950) y, posteriormente, triunfaron otros como desarrollo lingüístico (Noss 1967), reglamentación lingüistica (Gorman 1973), o gestión lingüistica (Jernudd/Neustupný 1987), que cubrirían el mismo universo conceptual del término acuñado por Haugen (1959). Sin embargo, ese concepto originario de "planificación" ha sido contemplado en los estudios posteriores a Haugen de dos maneras diferentes: ya desde una visión instrumental (Tauli 1974), ya desde un panorama sociolingüístico (Rubin/Jernudd 1975). La diferencia entre estos dos últimos tratamientos es la que separa el análisis de la lengua como puro instrumento - el cual debe pulirse para sacarle rentabilidad comunicativa-, y el de las actitudes de los hablantes ante ese medio de comunicación. Desde esta perspectiva, la labor de "planificar" no será igual para una lengua sobre la que se pretende una nueva creación o recreación (el hebreo, por ejemplo), en cuyo caso, hablaremos de "determinación lingüística", que para otra refrendada ya 
como lengua nacional, en donde propondremos el término de desarrollo lingüístico. No es, pues, extraño que haya sido la visión sociolingüística -más que la instrumental- la que haya motivado la deriva del análisis hacia consideraciones políticas e ideológicas, pues es aquí donde el roce de la lengua con lo externo a ella es mayor.

Creado el nuevo concepto, solo faltaba prepararlo para el análisis, y aquí fue donde Haugen (1959) diseñó un modelo de planificación articulado en cuatro estadios (dos de carácter social, y dos lingüísticos): selección (una variedad se convierte en el objetivo de la planificación); codificación (se dota a una lengua de gramática, ortografía y diccionario); implantación (se aúnan medios para su difusión), y elaboración (se plantean modificaciones que adecuarán el instrumento a las necesidades de comunicación). A estos, añadió luego Neustupný (1970) el de cultivo; Rubin (1975), el de evaluación (dotación de fondos por parte de un Estado), y Fishman (1974), el de orientación (o institucionalización, esto es, crear una lengua donde no la hay) y el de sustitución de un instrumento por otro. Como puede intuirse, los nuevos términos surgían no tanto de la necesidad de analizar la lengua como instrumento, sino del deseo de dar cuenta de cómo lo externo influía en el análisis lingüístico, por lo que Kloss (1969) tuvo la feliz idea de plantear una diferencia entre planificación del corpus (que trabajaría con cambios en la gramática, ortografía y léxico) y planificación del estatus (la posición social de una lengua respecto de criterios políticos, sociales o ideológicos de los gobiernos) (v. Moreno Fernández 2008).

Los modelos de análisis surgidos de los conceptos arriba mencionados adolecen, según Moreno Fernández (2008), de una escasa consideración de las lenguas como entidades continuamente mutantes, cuyos cambios no acontecen tampoco en paralelo con los que tienen lugar dentro de los esquemas sociales. Por esta razón, muchos de los términos neonatos creados por los sociolingüistas relacionan ideas que se adaptan más a un elemento externo que a otro: por ejemplo, los procesos de "determinación" adquieren un mayor sentido en las sociedades bilingües o en aquellas donde hay contacto con otras lenguas, mientras que en las monolingües el constructo más productivo debería ser el de "desarrollo lingüístico".

De otro lado, la diferencia planteada por Kloss (1969) entre planificación del corpus y planificación del estatus esconde dos tipos de agentes de intervención: los gramáticos particulares o instituciones académicas, por un lado, y las esferas de poder gubernamentales, por otro. $Y$ en este punto, es interesante el desgrane que podría experimentar la labor de "planificar" según las circunstancias especiales de la lengua focalizada como objeto de estudio (Moreno Fernández 2008: 343): 
1. El español ante sus variedades dialectales internas.

2. El español en territorios bilingües.

3. El español ante las variedades mixtas.

4. El español en países de lengua oficial diferente.

Sin embargo, cualquier tipo de planificación no escapa a los deseos de manipulación social y a las tentativas de control político, por lo que los objetivos que esta persigue no son exclusivamente lingüísticos, sino, sobre todo, de naturaleza simbólica (v. Christian 1992); por eso, Cooper (1997) es tajante en determinar que la planificación responde más a fines económicos (protección del consumidor), de intercambio científico, de integración nacional, de creación (o mantenimiento) de nuevas élites, de movilización masiva de movimientos nacionales y políticos, etcétera, que a motivos de carácter lingüístico. De aquí que podamos asentir con Cooper (1997) que la planificación lingüística pueda ser concebida como el estadio anterior a la creación de una política sobre la lengua, o, en otras palabras, que esta última tenga como objetivos a la primera; o que exista, como afirma Rotaetxe Amusategui (1990: 152) una "relación causal entre ambas". Este hecho llevaría a considerar la planificación lingüística como una subdisciplina de aquella que estudia la política sobre la lengua, esto es, la primera sería "una parte, o es la realización factual, de una política lingüística" (ibidem 72). Pero sea cual sea el juego de encajes inclusivos de una disciplina sobre otra, muchos sociolingüistas, entre ellos Hall (1950) -cuya obra refleja un título más que elocuente a este respecto (Leave your language alone)- muestran sus recelos hacia la nueva disciplina por los intentos de intervencionismo en lo social, ya que provocan inseguridad en el que habla, alejamiento de la oralidad y alteración del sentido en los procesos de mudanza lingüística; la misma idea que se esconde en los trabajos de Ferguson (1996). Esta postura (el rechazo a un cambio lingüístico deliberado) fue calificada por Tauli (1974) como anacrónica y precientífica, muy similar a aquella que rechazaba el control de las lenguas en el siglo XVIII; y sobre esta posición, Rosenblat (1984: 318) advertía que "dejar la lengua en paz [...] implicaría la repetición de la experiencia de Babel, la desintegración de la comunidad social". De todas maneras, este "dejar las lenguas en libertad" choca con el carácter no natural del objeto de estudio, pues la lengua funciona esencialmente por la intervención del componente humano y no se somete a reglas de causalidad como en las disciplinas naturales; así, como señaló Klein (1999), una obra de gramática o un diccionario, por más descriptivos que se presenten, influyen de manera distinta en aquellos escritos en los que las leyes relatadas no se prestarán a posibles manipulaciones o influencias de sus lectores (un libro de física, por ejemplo). 
En esos intentos de definir y precisar con mayor claridad la nueva disciplina, la planificación lingüística, abstraída de cualquier proceso de intervención política, encierra bondades en el acercamiento a su objeto de estudio, pues el hecho de planificar, como se advierte en Rubin y Jernudd (1975), podría ofrecernos respuestas interesantes a hechos como la elaboración de las gramáticas, a la creación de un estándar, al entendimiento de las reformas ortográficas, o a una mayor comprensión de la conformación de las distintas normas en un mismo o diferente territorio, hechos estos que podrían desempeñar un papel importante en el entendimiento de una identidad nacional.

Planteado de esta manera, como también advierte Rotaetxe Amusategui (1990), en la planificación de la lengua como instrumento (grafía, codificación, normas...), es donde el lingüista actúa más como agente interventor, frente a aquellas injerencias más relacionadas con los gobernantes, propias de una planificación del estatus.

Es así como los presupuestos teóricos han motivado llevar a cabo un conjunto de estudios prácticos que han acabado, muchas veces, corrigiendo algunos de los postulados sugeridos en el origen. La deriva hacia lo social $\mathrm{y}$, consecuentemente, hacia lo político ha motivado que las formulaciones teóricas no hayan partido de la lengua como instrumento.

Sin embargo, es indudable la interrelación existente entre los procesos de planificación política y las ideologías y actitudes ante la lengua en un periodo concreto del desarrollo de una norma, pues es el hablante el que, al fin y al cabo, reacciona para consolidar un fenómeno o desviarse de él. En este estudio, ante la imposibilidad de proponer encuestas como método de acercamiento al objeto -por razones obvias-, hemos de valernos de los textos en donde más caló la opinión pública en torno a la lengua -los de tipo periodístico-, los cuales, por su carácter de inmediatez, podrían dar mayor cuenta de la espontaneidad de los hablantes en estos componentes creenciales o actitudinales.

\subsubsection{Antecedentes metodológicos en el mundo hispánico}

En el mundo hispánico, el hilo teórico de los diferentes trabajos que han operado con los conceptos de planificación y política lingüísticas se resume en el término glotopolítica. Ha sido, quizá, Narvaja de Arnoux la investigadora que más haya contribuido al estudio de las normas, las actitudes ante la lengua y su relación con la política en el ámbito del español, y tanto en su vertiente histórica como sincrónica. ¿Qué entiende, pues, Narvaja de Arnoux, por glotopolítica? Quizá la mejor definición es la que se da en su publicación en coautoría con Nothstein (2013a: 9): "el estudio de las intervenciones en 
el espacio público del lenguaje y de las ideologías lingüísticas que activan y sobre las que inciden". Esta definición esconde un conjunto de posibilidades de análisis basado sobre todo en la intervención de los estados y de otros organismos de la sociedad civil en los asuntos lingüísticos, así como las transformaciones que han experimentado estos agentes de intervención a lo largo de la historia. El concepto que recubre la "glotopolítica" lleva aparejados términos como ideología lingüística o ideologemas, asociados a la noción de "tópica" (v. Angenot 1982; del Valle 2007; Narvaja de Arnoux 2013b; Wooland 2012), noción esta última de extremo interés para el análisis, pues permite enlazar la producción de discursos en torno a las diferentes lenguas aborígenes desde la prensa escrita. La mayor parte de estos trabajos analiza los problemas más actuales de lo que se denomina la "agenda glotopolítica" desde una visión panhispánica y regional, y aplicado sobre un corpus que incluye leyes, tratados gramaticales, diccionarios, congresos de la lengua o foros de internet ( $c f$. también Narvaja de Arnoux 2000; Narvaja de Arnoux, Elvira/Bein, Roberto 2010; Narvaja de Arnoux/ Bein 2015). Para el caso de Iberoamérica, son reseñables también los trabajos compilados por Bein/Born (2001). Muchos de estos estudios tienen como objetivo la incidencia de factores como la influencia del inglés, portugués o las lenguas indígenas en contacto con el español (Bein 2013; Niro 2013), las incidencias económicas (Varela 2013), o las tentativas prescriptivas en torno a España y los países latinoamericanos (Buisán 2013; Rizzo 2013; Roca 2013; Narvaja de Arnoux 2013a/), o políticas prescriptivas. En resumen, los postulados teóricos aplicados sobre la situación glotopolítica contemporánea del español vuelven a incidir sobre una posible sistematización de las influencias ejercidas por los poderes públicos en el ámbito de la lengua, tanto desde la perspectiva regional o panhispánica, como de lenguas en contacto.

De otro lado, desde una perspectiva más instrumental -y ya sea mediante el análisis del pensamiento gramatical o de incidencia real sobre la lenguapodemos citar estudios como los de Torrejón (1989), Gómez Asencio (2009), Rojas Gallardo/Avilés (2014a; 2014b), Rojas Gallardo (2015), o Rivas Zancarrón (2017a; 2017b; 2018a; 2018b; 2019a; 2019b; 2020a; 2020b; 2020c). 


\section{LOS TEXTOS PERIODÍSTICOS COMO FUENTE DOCUMENTAL}

La atomización de los estudios en torno a las actitudes lingüísticas y debate político sobre la lengua en el español de los siglos XVIII y XIX ha conducido tanto a una dispersión de los métodos de acceso al objeto, como a un tratamiento aislado de los contenidos propuestos, por lo que los corolarios no han llegado a ofrecer una visión panorámica de la interrelación que existe entre diferentes fenómenos y disciplinas. Desde un punto de vista metodológico, creemos que es necesario incidir en la conexión entre los modos de acceso de materias como la historia de la lengua (tanto en su acercamiento externo como interno) y los postulados que conforman la sociolingüística histórica. Esta interrelación presupone un enlace entre el funcionar de la lengua en una diatopía, diastratía, diafasía y diacronía concretas (en el sentido del Sprechakt bühleriano) y los requisitos externos para que una determinada actividad lingüística (Sprechhandlung de Bühler) se consoliden en un producto concreto (Sprachwerk), y desde una misma conformación lingüística (Sprachgebilde). Con el objeto de que la sociolingüística histórica llegue a ajustar sus puntos de anclaje con otras disciplinas, proponemos investigar las repercusiones políticas sobre la enseñanza del castellano en los últimos años de la Nueva España y los primeros del México independiente desde las actitudes implícitas o explícitas de sus hablantes como elementos de influencia comunitaria, y desde el marco de la intervención política de los gobernantes como medios de incidencia corporativa. La base textual de estas influencias tomará como fuente de estudio la prensa periódica.

Esta nueva fuente documental, creemos, podría arrojar nueva luz sobre la consideración de los fenómenos gramaticales en diferentes diatopías y en distintos espacios temporales -y tanto desde el punto de vista de una lingüística externa como interna-. Así, es cierto que muchos han sido los autores que han considerado la importancia de los medios de comunicación como agentes de influencia y reflejo de la opinión pública, pero pocos son los que se han atrevido a explorar sus repercusiones desde un punto de vista práctico. A este respecto no tenemos más que leer palabras como las de Heller (2010: 44) -que fueron escritas desde las sugerencias de Fairclough (2001)-, para ratificarnos en esta idea: "if ideology is pervasively present in language then the influential position of, say, newspapers to inform and influence readers is a particular interesting vehicle of ideological transmission". Es así como la prensa periódica se erige en espacio discursivo idóneo para la "construcción de lo nacional y sus deslindes, así como la maquinaria de 
lo público para la afirmación del Estado, lo cual implica que sea en ese entramado que se propicie la mediatización y circulación de ideologías lingüísticas" (Ennis/Toscano y García 2019: 2). De esta manera, en la construcción de la identidad lingüística de toda "comunidad imaginada" (Anderson 1983) son esenciales tres categorías de las que la prensa (y entiéndase por prensa el colectivo encargado de emitir este producto cultural) hace uso: la legitimidad, el poder y la autoridad (Bourdieu 2001). En la cuestión del idioma, estas autoridades suelen conocerse como "guardianes de la lengua" (language meavens, Heller 2010), y son, tradicionalmente, periodistas que promulgan el buen uso o censuran la incorrección (los llamados "higienistas verbales" en Cameron [1995] o en Milroy/Milroy [1999]). Por tanto, es inevitable no considerar el papel primordial que ejerció la prensa en la estandarización de la norma lingüística de cada territorio hispanohablante y en la legitimación del prestigio o la condena de determinadas variedades del español (Blommaert 1999; Fairclough 1996). Y, más concretamente para el ámbito hispánico, el papel de la prensa en estos procesos ha sido referido por autores como Ramírez Castañeda (2006), quien incide en cómo estos textos se convirtieron en adalides de la educación con el surgimiento de opiniones que recomendaban o censuraban materiales para la enseñanza de la lengua. Desde un punto de vista político, este espacio de opinión pública fue decisivo en los cambios de orientación sobre política lingüística; así Aguirre Beltrán (1972), por ejemplo, advierte de las repercusiones que tuvieron durante el porfiriato mexicano, o como nuevo lugar laico en sustitución del púlpito para las formas de expresión lingüística y discursiva ${ }^{3}$.

Téngase en cuenta que existe una relación directa entre la aparición de la prensa periódica y el incremento de lectores a finales del siglo XVIII, pues los contenidos que esta ofrecía eran más atractivos para un público menos avezado en la comprensión de contenidos, que exigían estudios previos y que se manifestaban con formas más alejadas de la oralidad.

De otro lado, el proyecto ilustrado necesitaba de un canal de difusión para sus ideas, de un medio que posibilitara hacer llegar su mensaje al mayor

\footnotetext{
En Lemus (2020: 17-18), se insiste en la importancia de la prensa como medio para conocer el pensamiento ilustrado de la época y el desarrollo de los avatares históricos: "El periódico, visto como el constructo cultural de una sociedad determinada, está siendo revalorado no sólo como fuente de datos, sino como objeto de estudio en sí mismo, como han sugerido Latham y Scholes (2006). Para esos autores, en años recientes, los estudios de las publicaciones periódicas han servido tanto a los estudiosos de la historia como a los de la literatura para allegarse a nuevas fuentes y crear nuevos cuestionamientos sobre los paradigmas existentes respecto a la Ilustración, al siglo xIX y a la cultura contemporánea en general".
} 
número posible de la población, pues el futuro de la sociedad se asentaba sobre los pilares de una buena educación, y tanto en su sentido científico, como cívico y lingüístico. Shirley Brice (1972: 96) resumió con enorme lucidez el papel que ejerció la prensa periódica desde finales del siglo XVIII:

A través de las páginas del Diario de México, panfleto semanal establecido a principios del siglo xix, corrían comentarios y nuevos datos que reflejaban las preocupaciones de los españoles que ansiaban modelar la cultura de la nobleza de la Nueva España según los mejores modelos europeos. El Diario informaba lo que concernía "Al bien de la sociedad" [...], causas célebres que deberían darse a conocer a todos los "buenos ciudadanos". Los que escribían exigiendo uniformidad en el vestir, las costumbres y la educación, adoptaban como normas las mejores tradiciones europeas. Jacobo Villaurrutia, cofundador del Diario, proponía un colegio que impartiera, a través de su programa, la enseñanza del francés, "lengua viva universal", y en el quinto año de estudios, latín y español. El primero era necesario debido a su uso continuo en el ejercicio público, y ambos idiomas eran útiles por sus "ideas generales" que podrían encontrarse en todos los idiomas.

La voz de los intelectuales ilustrados de la época en la Nueva España, criollos en su mayoría, se dejaba escuchar a través de las publicaciones periódicas, en donde se presentaban y debatían propuestas ante una opinión pública, que, después, podía alcanzar el rango de leyes. Se hablaba de libros publicados, de gramáticas adecuadas para la enseñanza del castellano, de creación de escuelas para niños y niñas, de la educación para indios, de la pureza o corrupción del español en las tierras conquistadas, de la forma de hablar de los aborígenes no criollos ni españoles...; en definitiva, de un sinfín de temas que calarían, sin duda, en las creencias y actitudes de los hablantes y que contribuirían a trazar los nuevos caminos que tomaría el castellano en esas tierras.

El tipo textual periodístico que se produjo en esa época en la Nueva España y en el México independiente se compuso mayoritariamente en español, aunque, como señala Lemus (2020), con frecuentes alusiones a autores latinos y griegos y con una gran proliferación de palabras locales e indígenas. La recepción de estos textos se dirigía hacia, fundamentalmente, criollos ilustrados -los encargados, a su vez, de su redacción-, jerarcas locales y el alto clero. El objetivo que canalizaba estas publicaciones inmediatas se dejaba leer explícitamente en los prospectos bajo expresiones como "servir al bien común", concepto este de los más repetidos en el periodo ilustrado. Y si hay un constructo político de especial relevancia para la construcción de las diferencias lingüísticas, y cuya evolución pudo seguirse en el devenir de las 
publicaciones periódicas, ese fue el de "nacionalismo" y, consecuentemente, el término de lengua nacional. Fue en torno a este, y desde su indisociable prisma político, desde el cual se creó también una conciencia lingüística sobre el vehículo que debía servir de comunicación para un territorio y sobre las peculiaridades diferenciadas que este instrumento debía adquirir en el nuevo espacio.

Por último, el hecho de que se le otorgue a México el papel de haber sido el precursor del periodismo en América no se debe a otra circunstancia sino a que fue en este territorio donde se introdujo la primera imprenta (1536). Antes de que llegara la primera publicación periódica seria en el siglo XVIII, la Gaceta de México y noticias de Nueva España (1722), se imprimieron también folletos y panfletos con noticias varias -las llamadas "hojas volantes"-, que informaban sobre los pormenores de sucesos extraordinarios. No obstante, el elevado índice de analfabetismo, el alto precio del papel y la intervención de una férrea censura contribuyeron a que el volumen de publicación no fuera el deseado.

En los epígrafes que siguen a continuación, y una vez contextualizado el entorno metodológico y político-social, daremos cuenta de aquellas variables que pudieron contribuir -desde las actitudes de los hablantes en los espacios de opinión pública- a la construcción de un debate político en torno a los destinos del español como vehículo de comunicación. En aras de una planificación de la norma y del estatus exitosas, la prensa actuaría como un globo sonda de la opinión pública. Hemos querido dividir en tres periodos los textos documentales seleccionados (1722-1810; 1810-1821 y 1821-1830), que refieren a las franjas históricas de inicio de la prensa periódica en la Nueva España (1722) hasta la insurgencia (1810); de aquí, a la Independencia de México (1821), y desde esta fecha hasta los primeros años de la nueva nación libre. Igualmente, las manifestaciones en torno al castellano en los periódicos se dejan resumir en variables como la intervención de la Iglesia y del Estado, la creación de escuelas de primeras letras, la situación indígena ante el castellano y la transmisión de las ideas gramaticales mediante métodos y manuales. 


\section{POLÍTICA, GRAMÁTICA Y ENSEÑANZA DEL ESPAÑOL EN LOS ÚLTIMOS AÑOS DE LA NUEVA ESPAÑA Y PRIMEROS DEL MÉXICO INDEPENDIENTE: UNA APROXIMACIÓN DESDE LA PRENSA PERIÓDICA}

\subsection{Iglesia, Estado y Lengua}

\subsubsection{Periodo de 1722 a 1810}

Entendida en sus orígenes la castellanización como un proceso que escondía la conversión a la doctrina cristiana de los pueblos conquistados por los españoles, la política que siguió la Corona estuvo supeditada durante largo tiempo a decisiones eclesiásticas. Los frailes misioneros veían más factible llevar a cabo la cristianización de los nuevos territorios con el aprendizaje de las lenguas vernáculas, que imponiendo para ello un sistema de comunicación ajeno al universo lingüístico de sus legítimos pobladores. En este sentido, ya anunciaba Alfonso Caso (1973) que el enfrentamiento entre Iglesia y Estado pasaba por resolver primeramente el problema lingüístico, y en esta batalla fue la institución eclesiástica la que poco a poco ganaba terreno a las decisiones de la realeza gobernante, que en vano emitía cédulas en favor de la castellanización. Consiguió el clero que tanto sus Concilios particulares (Lima 1551-1552; 1567; 1582-1583), como los celebrados en territorio europeo (Concilio General de Trento, 1545-1563), apostaran por la evangelización en lenguas indígenas, por lo que el Estado no tuvo más remedio que aceptar la creación de cátedras que enseñaran los lenguajes prehispánicos. La política más "federalista" de los austria motivó que los deseos eclesiásticos se impusieran sobre los gubernamentales, pese a la insistencia machacona del último de sus monarcas, Carlos II, quien se empeñó mediante continuas reales cédulas -allá por los últimos años del siglo XVII- en hacer valer la supremacía del castellano. A partir de ahí, y con los Borbones - más centralistas en su concepción de gobierno- la postura de la Iglesia comenzó a perder fuerza, una debilidad minada en los primeros momentos por los Decretos de Nueva Planta (1707-1716) de Felipe V y, más tarde, por la Real Cédula de 1770 emitida por Carlos III a sugerencia del arzobispo Lorenzana. Esta lucha por el control de la lengua (o de las lenguas) influyó decisivamente en la consideración del castellano como vehículo comunicativo, que debía enseñarse de acuerdo con un modelo y un método gramatical, el cual debía responder también a una norma determinada ( $c f$. Lodares Marrodán 2006). 
Este universo político-social se vio reflejado en la prensa de la Colonia desde sus primeros momentos. En la Gaceta de México encontramos continuas referencias a la creación de cátedras tanto de castellano como de lenguas indígenas, en donde la Iglesia aún mostraba su fuerza:

(1) Este mismo dia se dedicó el Insigne Colegio de la Purissima Concepcion, que (por Bula del Señor Urbano VIII. del dia 5. de Octubre de 1624) fundô Pedro Nuñez: en èl se leen Cathedras de Gramatica, Humanidad, Rectorica, Artes, Theologia, que cursan Religiosos, y seis niños, nobles y pobres, Colegiales de manto azul, y beca blanca, y en ella la Imagen de la Concepción, y los Venerables Agreda, y subtil Escoto, de cuya doctrina tambien se haze explanacion, por vn Lector Jubilado, los cursos del sobre dicho Colegio, valen para que sus Estudiantes se gradúen en la Universidad de México (Gaceta de México, 1/12/1729: 6).

(2) Componese esta Provincia [Santa Helena] de diez y seis Conventos, vna Assistencia, quatro Lecturas de Theologia Escolastica, vna de Moral, dos de Artes, quatro de Grammatica, quatro de Idioma, vna del Timucua, otra del Yamas, otra del Amaleche, y otra del de la Costa, nueve Predicadores Conventuales, y cinco Comissarios del Tercero Orden (Gazeta de México, 1/7/1732: 5).

(3) Hase erigido nuevamente en esta Universidad Cathedra de lengua Cakchiquel, y la frecuentan muchos cursantes, y de ellos, los mas Clerigos, que obedeciendo el mandato del Illmo. Señor Obispo, se han dedicado á aprender este idioma, porque dessea su Illma. que todo el Clero estè apto para la administracion de los Indios de su cargo, en cuya conformidad ha resuelto no ordenar â ninguno in sacris, sin que conste de su suficiencia en alguno de los Idiomas de su Diocessis (Gaceta de México, 1/4/1731: 5).

En este último texto, se observa el apoyo eclesiástico al aprendizaje de las lenguas indígenas, pese a los intentos de castellanización por parte de la Corona. Téngase en cuenta que a los sacerdotes les interesaba el mantenimiento de las lenguas vernáculas, pues esta circunstancia favorecía la presencia de un clero criollo frente al peninsular, ya que se exigía el dominio de alguna lengua prehispánica a los curas que regentasen una parroquia. De otro lado, a los criollos no les interesaba que los indios aprendieran a hablar castellano, pues les amenazaba "el sistema de estratificación social que suponía la superioridad del español y la inferioridad del indio" (Heath 1972: 76). Y tampoco favorecía a algunos indios que dominaban el castellano, sobre todo a los que servían de intérpretes - los conocidos como naguatlatos-, pues estos encontraban en sus destrezas lingüísticas una forma de distinguirse de 
sus congéneres. Por ello, la prensa continúa reproduciendo la asignación de los sacerdotes según la lengua que dominan:

(4) Assimismo tiene en el Mesquital Doctrinas, en Tecama de lengua Mexicana, dos Religiosos. En Tetepanco de lengua Otomi, y Mexicana, dos. En atocpan de Otomi, ocho. En Yoletepec de Otomi, dos. En Chilquauhtlan de Otomi, dos. En Chiapatonco de Otomi, dos. En Yxmiquilpan de Otomi, ocho. En Chichicaztlan de Otomi, dos. En Chapulhuacan de Otomi, dos. En Xilitlan de Mexicana, dos. En Xalpan, de Otomi, dos. En Xiliapan de Otomi, dos. Assimismo tien la Doctrina de Mitzquie de lengua Mexicana, con dos Religiosos. En Ayotzinco de Mexciana, dos. En Tetolapan de Mexicana, tres. En Tlalnepantla de Mexicana, dos. En Atlatlautan de Mexicana, dos. En Yacapiztlan de Mexicana, quatro [...] (Gazeta de México, 1/1/1735: 4).

Con la expulsión de los jesuitas en 1767 y la emisión de la Real Cédula de 1770, el peso de la Iglesia en los procesos de planificación lingüística comenzó a decaer. Desde este momento, la enseñanza del castellano se convirtió casi en un proyecto ilustrado, pues las diferentes ramas del conocimiento, esenciales para la mejora cívica y moral de los pueblos, quedarían mejor exploradas por lenguas como el español. Se hacía necesario, por ello, crear escuelas que sufragasen, sobre todo, las necesidades lingüísticas de la población y que les enseñase a leer y escribir. Y cuanto mayor fuera el número de lectores, mayor sería también el radio de influencia de una prensa periódica que solo alcanzaba, de momento, a la nobleza y al clero criollos.

\subsubsection{Periodo de 1810 a 1821}

Durante este periodo convulso, en donde las instituciones políticas y religiosas sufrieron la polaridad de gobernanzas inestables, la educación y la enseñanza del castellano no constituyeron prioridad, aunque la lengua sí fue un objeto de las caricias de una población criolla que veía cada vez más cerca la conversión de su "patria" en "nación" -frente a la heterogeneidad de las lenguas vernáculas y la despreocupación por lo político de sus hablantes- un vehículo de comunicación que favorecería la nueva unidad, pero, por otro lado, el cuidado del castellano no experimentó mejoras desde el sistema legislativo, pues perduraban aún

\footnotetext{
4 En Lemus (2020), se relata la diferencia entre los términos de patria y nación (el primero más localista), que, indudablemente, tuvo repercusiones en la denominación del castellano y en su distinción respecto de las lenguas habladas en territorio americano.
} 
las viejas ideas de la colonia en los sistemas de enseñanza. Desde el grito de Hidalgo (1810), se suceden múltiples pronunciamientos ideológicos e intentos de redención de los insurgentes, apoyados por la frescura de ideas liberales llegadas desde la Constitución de Cádiz (1812), que pondría fin al imaginario colonial. Desde ahora, los españoles se convertirán en adversarios y los criollos -que incrementarán su odio hacia el indio- se erigirán en la nueva clase dominante. Desde estos momentos, no interesa evangelizar, sino construir un nuevo Estado, en donde los antiguos pobladores y sus lenguas se mantendrían como vestigios de un pasado que debía estudiarse, pero no revivificarse. Desde ahora, la misión de la Iglesia perdía su sentido. El 22 de octubre de 1814 se promulgaba la Constitución de Apatzingán, en donde, paradójicamente, el indio, elevado a la categoría de ciudadano, recuperaba su dignidad como pueblo, pero perdía, consecuentemente, sus privilegios como grupo marginado, y con este se difuminaba el papel de una Iglesia volcada en el cumplimiento de esas prebendas.

Desde las Cortes de Cádiz, la prensa dio cuenta de cómo los indígenas - gracias a ese cambio de estatus social- eran privados de sus bienes, que debían transferirse a las nuevas unidades administrativas - los ayuntamientos-. Y si antes habían sido las comunidades las responsables de la educación, ahora serían los cabildos los que, sin dinero para ponerla en funcionamiento, devolvían la responsabilidad a los indios, los cuales solo dispondrían de escuelas si podían pagar al maestro ( $c f$. Staples 2011). Cuando mudó la estructura política hacia los ayuntamientos constitucionales, las pequeñas poblaciones que no alcanzaban el número de habitantes necesarios para formar cabildo propio se vieron abocadas a la pérdida de sus escuelas, pues solo pueblos con ingresos superiores a los 60 pesos anuales podían gozar de educación; si no se daba el caso, las familias debían costear al maestro. Según Staples (2011), las prioridades de las escuelas constitucionales, que vivirían la ordenanza de la supresión del gremio de maestros en 1814, fue la asignación de estas a jóvenes ladinos y mestizos y, después, a los niños indígenas. Y en este proceso, la educación religiosa fue la que más perdió, pues acabó satanizándose desde un punto de vista ideológico. En este periodo, se creó el germen de una conciencia nacional de carácter urbano, ilustrado y criollo, pero la ausencia de dinero impidió que la ideología encontrara un asiento efectivo. Durante este proceso, la prensa periódica, más dedicada a los reportes de guerra en España y a las revueltas de los insurgentes en la Colonia, da muestras de cómo el indio debía ser un pilar para los criollos en la lucha por la independencia, al que se le trataba de convencer en sus lenguas nativas: 
(5) En efecto, procuré que con los indios de Chipoco, sus mas inmediatos vecinos, se les remitiese un papel en idioma mexicano á los indios de la cabecera, ofreciendoles la real gracia del indulto y la proteccion de las armas de la nacion para sostenerlos contra sus opresores (Gazeta de México, 31/3/1813: 4).

Estrategias lingüísticas estas de una nueva clase dominante, que, una vez conseguidos sus objetivos, intentarían someter a los pueblos indígenas con una "lengua de la razón":

(6) Como gefe de este distrito interesado en executar las disposiciones beneficas de la superioridad dirigidas á vuestra felicidad, busco todos los medios para que os penétreis del idioma suave, de quien por otros podia haceros conocer el camino de la razon de que tanto tiempo estan extraviadas (Gazeta de México, 1/9/1813: 938).

Ahora, en el camino hacia un Estado diferente, el nuevo poder difuminará la misión evangelizadora y priorizará la lingüística, en donde el nuevo dios será el castellano.

\subsubsection{Periodo de 1821 a 1830}

Una vez consumada de facto la independencia mexicana, el Estado se ocuparía ahora del control de la educación y de la enseñanza de la lengua. La Iglesia, más ocupada en la evangelización que en el desarrollo educativo, perdería su poder de supervisión y solo el Catecismo de Ripalda, mantenido como libro de texto hasta 1861 , recordaría la huella eclesiástica de otros tiempos. Con la recién inaugurada República Federal de México (1824), fue prioridad de sus gobernantes la construcción de un sistema educativo que llegara a todos los rincones de la nueva nación, pero, como advierte Arredondo López (2011: 373), el nuevo territorio "libraba una batalla a muerte entre dos culturas: por un lado, la cultura emergente en la localidad, criolla y mestiza, que pugnaba por reproducir y ampliar la cultura occidental, ilustrada; y, por el otro lado, la cultura de los llamados bárbaros, que luchaba por sobrevivir, acosada por el empuje de la modernidad". El problema del indio y de sus lenguas, manejado durante tantos siglos por la Iglesia, se trasladaría a la administración del Estado, el cual, elevando a este grupo a la categoría de ciudadano, y bajo la excusa de una nueva libertad, acabaría por resolver el debate lingüístico y de costumbres desde el fin necesario de crear una nación unida y homogénea: había que castellanizar al indio y, a su vez, hacerle ver que se respetaba su cultura. 
Durante esta década, la prensa reivindicará constantemente la importancia del texto y de una cultura escrita como forma de sacar a sus ciudadanos de la barbarie. Al Estado se le reclama su presencia en la instrucción y se le exige que fomente una "lengua de razón":

(7) A fuerza de experiencia se instruirá; á fuerza de errores se corregirá; y será prudente y bueno por que tiene interes en serlo: comunicandose una nacion, las ideas de unas clases á otras, la instruccion será general y vulgar la ciencia... (Fanal del Imperio Mexicano, 15/5/1822: 163).

Para la nueva nación que comenzaba a forjarse, la instrucción debía constituir el objetivo primordial del Estado:

(8) En todas estas disposiciones, nada de quimerico, nada de imaginario, nada que huela á delirios de academia, nada que sea imposible de realizarse; cosas infinitamente mas dificiles se han emprehendido y llevado al cabo en el periodo prolongado del despotismo, ya para nuestra servidumbre, ya para satisfacer necesidades demasiado secundarias para que puedan compararse con la de la instruccion, que es la gran palanca del hombre, y la unica tabla que puede salvarnos del naufragio en que casi ha perecido del todo nuestra libertad. Una imprenta, surtida de una cantidad abundante de letras de los carácteres corrientes de lectura, de anatanasia y de texto, con un par de buenas prensas, apenas tendrá de costo dos mil pesos. ¿Los ayuntamientos de las capitales que gastan sumas mucho mas fuertes en empedrar calles, formar paseos, \&c. \&c. \&c. podrán quejarse de que faltan recursos para costear imprentas de esta clase? (Fanal del Imperio mexicano, 15/5/1822: 282).

Estas publicaciones periódicas no tienen por menos que defender la necesidad de que el castellano se convierta en "lengua nacional" entre los pueblos americanos, y no solo por una cuestión de tradición escrita, sino porque sus hablantes son mayores en número que en la propia Península:

(9) Aunque no seria justo ocupar las pàginas de un periódico con obras ya publicadas, las circunstancias de este papel lo hacen, en parte una escepcion á la regla general. Como se escribe en Inglaterra donde hay personas aficionadas á la lengua castellana, y se dirige principalmente á América donde trece millones de habitantes la tienen por habla nacional, no es posible que los lectores de la una ó la otra clase lleven á mal el ver en él producciones bellisimas que, por falta de abundancia de libros españoles, tarde y con dificultad llegarian á sus manos (Águila mexicana, 12/8/1824: 4). 
Para el criollo que escribe habitualmente en estos espacios de opinión, el español debe ser considerado como un vehículo de unificación de ideas, frente a la heterogeneidad de las otras lenguas habladas en sus territorios. El debate político para construir una nueva nación no tenía cabida sino en español, que, además, debía orientarse hacia una pureza medida por el rasero de sus hablantes minoritarios, los peninsulares: "El idioma de las leyes debe ser el comun de la nacion que ha de observarlas. Escribir las leyes en un idioma extranjero es tender redes en que coger á los que no le han estudiado" (Fanal del Imperio mexicano, 15/5/1522: 200). Y es precisamente en el proceso de construcción de las leyes donde la lengua tiene que afinar más; por eso, los debates políticos reflejados en la prensa periódica de esta década comienzan por discusiones sobre el significado real que tienen determinadas palabras:

(10) Igual divergencia de opiniones suele haber en la inteligencia de la palabra orden aplicada à la administracion de la hacienda pública y demas ramos en que estriva la prosperidad de las naciones ( $E l$ Nivel, 5/7/1825: 2).

(11) Tambien es preciso fijar el sentido de la palabra aceptacion para quitar toda clase de duda, que en este asunto seria grave y delicada: si ha de ser tan espontànea dicha aceptacion, que no se obligue á contribuir mas de aquellos que voluntariamente quieran comprometerse... (El Invitador, 19/6/1826: 218).

(12) Me parece que la idea que tenemos de la palabra lujo, no abraza los objetos de este género. De la voz latina luxuria se han formado dos palabras lujo y lujuria (El Invitador, 22/12/1826: 352).

\section{De la palabra política}

Este vocablo que por la adulteracion de su significado y el proteísmo de su aplicacion parece anatematizada desde su origen conserva un resto de reprobacion hasta en sus últimas ramificaciones. Entre los gabinetes es un sinonimo de delito, entre la sociedad lo es de mentira. Por politica no se dice lo que se piensa... (El Nivel, 6/4/1826: 3).

La prensa, convertida en diario de sesiones del congreso, da también continuas muestras de los debates lingüísticos para la redacción de las leyes:

\section{Sesion del dia 9}

Se puso à discusion el $2^{\circ}$ artículo del acta constitutiva.

El sr. Vargas, como de la comision, dijo, que ésta habia convenido en suprimir la clàusula de soberano de si misma. 
El sr. Rejon: que se oponia al artículo, no en cuanto al sentido, sino à los términos en que estaba redactado (El Iris de Jalisco, 18/12/1823: 35).

Poco a poco, la figura del gramático o del literato cobra fuerza en el mundo de la política, pues será este quien ayudará a desambiguar las leyes mediante la palabra y quien reconducirá la enseñanza del castellano en las escuelas a través de los programas oficiales y los libros de texto: (15) "Todo literato sabe que la voz diezmo no ha significado siempre una parte de diez como se cobra aqui: sea de este ò no la opinión mas seguida, es preciso fijarse" (El Iris de Jalisco, 7/1/1825: 2). Esta figura, no obstante, se colorea de sabiduría humanística y se hace esencial en el debate político, pues ya no será solamente un conocedor de la etimología griega o latina, sino que ayudará al proceso de instrucción de un pueblo: (16) "El espiritu del siglo los ha hecho [a los literatos], por la mayor parte, tan aptos para el gran mundo, como para el gabinete; y en esto son muy superiores à los literatos, de los siglos precedentes, tanto, que se han hecho ya una parte necesaria al gobierno de toda una nacion civilizada" (ibidem).

\subsection{Políticas EN TORNO A LA ENSEÑANZA DEL CASTELlano}

\subsubsection{Periodo de 1722 a 1810}

Existe una idea generalizada de que la educación y la enseñanza de la lengua fue casi inexistente en el periodo colonial, o que esta fue pagada fundamentalmente por las instituciones eclesiásticas; sin embargo, como opina Tanck de Estrada (2000: 337), "las escuelas de primeras letras en más de mil pueblos indios eran sostenidas por las cajas de comunidad y por los padres de familia. Después de la promulgación de los reglamentos de los bienes de la comunidad, solo en algunos casos aislados el párroco pagaba al maestro o los frailes ofrecían enseñanza a los indígenas". Naturalmente, nos enfrentamos con un territorio en donde existen lenguas en contacto y en donde los intereses por dar primacía a una y a otras dependían de los criollos y del clero. Por supuesto que la población indígena gozó de educación, pero esta estuvo dirigida por una Iglesia que trataba de favorecer sus propios intereses. Las órdenes reales se difuminaban por la lejanía, hasta el punto de que en 1728 se dio una intervención paradójica: descendientes de nobles indios solicitaron al Arzobispo de México que se abriera el Colegio de Tlatelolco (fundado por los franciscanos en 1536) y que se programara la enseñanza del español a los indios (v. González Luna 2012). Ya hemos visto que la enseñanza del castellano a la población indígena no fue una materia bien recibida por los criollos y el clero, pero esta situación cambió por el mayor 
control que ejerció la Corona a partir de la Real Cédula de 1770 y por los cambios en la administración territorial: en 1786 se creó la Real Ordenanza de Intendentes para la Nueva España, por la que los Ayuntamientos dejarían de ser independientes y pasarían a ser controlados por el gobierno virreinal. A esto, vino a añadírsele el intento de supresión de los gremios y sociedades corporativas por parte de Carlos III, una idea pergeñada por Campomames y Jovellanos, pues consideraban estos que restaba libertad a la producción y controlaban el proceso educativo. Una consecuencia de estas ideas fue la abolición del gremio de maestros (congregación de San Casiano) en 1780, por lo que los preceptores de primeras letras podrían ejercer libremente y sin control, aunque bajo la supervisión de un "colegio académico", el cual discutiría el programa de estudios de la enseñanza primaria con la creación, a partir de 1786, de escuelas gratuitas, y regularía los libros de texto ${ }^{5}$. Todas estas circunstancias tuvieron reflejo en la prensa a través de la Gaceta de México, que, a partir sobre todo de la nueva ley de Intendencias, relataba la creación de escuelas por los diferentes pueblos y ciudades. Una muestra representativa de este interés por el funcionamiento de una escuela es el texto siguiente, en el que se describe el plan de actuación del colegio San Juan de Letrán, y en donde la gramática ocupaba las primeras y últimas horas del día:

\section{PLAN}

\section{DISTRIBUCIÓN DIARIA}

1. Luego que se dispierte por la mañana (que en tiempo de Invierno será á las cinco y media, y en el Verano á las cinco) procurarán ofrecer su corazón á Dios, pidiéndole las gracias necesarias para cumplir con sus obligaciones christianas y escolásticas. Se levantarán prontamente, se vestirán con modestia y en silencio, se peinarán y lavarán las manos y cara antes de salir de sus Quartos.

2. A las seis ó cinco y media (segun los tiempos) se tocará la Campana, y saldrán todos inmediatamente para la Capilla, donde se les leerá alguna

5 Durante el periodo virreinal, el municipio era el encargado de supervisar la enseñanza pública de primeras letras a través de la Junta de Gremios, pues los docentes se regían por las normas del "Gremio de maestros del nobilísimo arte de las primeras letras", fundado en 1601. Este gremio era controlado por un regidor especial del ayuntamiento y un juez de informaciones de maestros que se encargarían luego de expedirles un título legal, después de que comprobaran su legitimidad, pureza de raza y buenas costumbres. Este gremio fue sustituido a finales del siglo XVIII por las leyes de Intendencia. Muchos de los preceptores ejercían, no obstante, sin pertenecer al gremio y fueron denunciados como "intrusos" (v. Arredondo López 2011). 
instruccion sobre la Religion ó la Moral, la qual durará quando mas un quarto de hora [...].

6. Dadas las nueve se tocará á Aulas hasta las once para los Filósofos y Gramáticos; y los Teólogos y Juristas preparán sus materias para la Cátedra, ó en sus Quartos ó en los Corredores.

7. A las once baxarán estos á sus Aulas, y del quarto hasta las doce estudiarán los demás en los Corredores [...].

Debe advertirse que los Estudiantes de primeras letras en las horas de estudio, en que no están en la Escuela, ni en recreacion, han de leer en algun Catecismo ó en el librito de las Reglas de buena crianza, y los mas adelantados tomarán de memoria las Reglas de la Ortografia y Gramática Castellana de la Real Academia Española (Gazeta de México, 21/9/1790: 20).

Igualmente, la prensa informaba sobre los actos públicos de celebración de exámenes, acontecimientos muy celebrados por las autoridades civiles y eclesiásticas, en donde se premiaban a los mejores estudiantes:

(16) Se han repetido en esta Villa en los dias 20, 22 y 24 del anterior los Actos públicos de primeras letras, establecidos desde el año pasado en la Escuela fundada por el Señor Coronel Don Ignacio Obregon, y á cargo del Maestro exâminado Don Joseph Anacleto Cubero. Este Profesor hizo un convite solemne; ofreciendo que en tres dias serían exâminados de las primeras Letras diez y ocho niños gratuitos y de paga, y Alumnos de dicha Escuela [...].

Los seis niños del segundo Acto y de la segunda parte del Curso [...] referirían lo mismo que los anteriores, y ademas dirían de memoria doce extensos pasages de la Sagra Escritura, desde la creación del Mundo hast la segunda edad de él, las quatro partes de la Doctrina Christiana, y lo que era Iglesia con sus divisiones en Triunfante, Militante, \&c.: que dirían igualmente de memoria todo el libro de educacion, que con arreglo á la Sagrada Escritura publicó Don Pedro Septien: que dirían los compendios de Gramática y Ortografía castellanas formados por su Maestro, con arreglo á la Real Academia Española, y que harían régimen de uno y otro en qualquier Libro ó Manuscrito que se les presentase [...] (Gazeta de México, 21/10/1794: 1).

Estos concursos ensalzaban o ponían en tela de juicio la labor de los instructores, la cual se centraba fundamentalmente en la enseñanza de la lengua, sobre todo de la ortología, ortografía y caligrafía: 
(17) Dicho D. Mariano Veraza trató con instruccion y propiedad sobre el modo de tomar la pluma segun Palomares, hablo de la Gramática Española, sobre el Viejo y Nuevo Testamento, de algunos puntos relativos a la Policía, y saco algunas cuentas curiosas. [...] Se trató sobre la propiedad de la Ortología, todas las combinaciones posibles de las vocales, distincion de C. Z. S., silabas, monosilabas, disilabas y demas divisiones de ellas: definiciones de la letra, palabra y todas las notas de puntuacion. Reunieron con propiedad los diptongos y triptongos de nuestra lengua, trataron de los nombres y verbos castellanos, y aun tenian las distinciones y divisiones de todas las partes de la oracion, aunque el tiempo no dio lugar á tratar de ello (Gazeta de México, 27/3/1793: 2).

Y las referencias a las vacantes de maestros, que podían ejercer sin tener que pasar por los gremios, eran constantes, con información sobre sueldo y materias que debían impartir (normalmente, destinados a la enseñanza de la lectura, escritura y religión):

(18) En esta Ciudad [Zacatecas] se halla vacante la plaza de Maestro de primeras letras, cuya dotacion anual es de quatrocientos cicuenta y seis ps. que se le satisfacen en Caxas Reales por tercios de año, y ademas se le dá tambien casa para su habitacion. Los individuos que deseen conseguir este destino dirijan su solicitud con los comprobantes de habilidad y conducta á Don Pedro de Torices, Síndico Procurador de dicho Cabildo, quien oportunamente les contestará, para que le sirva de gobierno (Gazeta de México, 15/4/1803: 11).

La distinción entre escuelas para niños y niñas existió desde los inicios y la prensa también se hizo eco de una división que, además de considerar materias comunes como las de enseñar a leer, escribir o contar, se les agregaba otras acordes al sexo (bordar, tejer, etcétera). Igualmente, se daba noticia de los exámenes públicos de estas escuelas de primeras letras para niñas:

\section{GUADALAJARA}

El dia 16 del próximo Agosto se trasladaron de su antigua habitacion pobre, vieja, y arruinada, las Beatas, que con el nombre de Claras se habian congregado á solicitud del piadoso Tesorero Marcos Flores, á la nueva Casa, que con bastante amplitud y hermosura se fabricó á expensas del Illmô. Señor Obispo de esta Diecesi [sic], junto á la Parroquia y Santuario de Nrâ. Srâ. de Guadalupe, con el título de Congregacion de Maestras de la Caridad y Eneseñanza, por ser el objeto de sus Ministerios el de una pública Escuela, donde aprendan las Niñas que quieran concurrir á ella, la Doctrina Christiana, y las Artes de ler, escribir 
y contar, hacer rosas, labrar, bordar, texer lana, algodon, lino, seda, y metales en galones, con otras cosas propias de su sexô. El distintivo de las Beatas, que antes era Habito azul de S. S. Francisco, se ha mudado en un ropage negro, á semejanza de el de la Enseñanza de México (Gazeta de México, 8/9/1784: 1).

(20) En Durango: “La Cofradía de nuestra Señora del Tránsito, presidida por el Señor Gobernador Intendente, celebró el dia 12 del corriente el primer exâmen público de las Niñas de la Escuela establecida segun sus Constituciones arregladas á lo particular, y expresamente prevenido por el Supremo Consejo en quanto á que quando sus fondos lo permitiesen, se empleasen con preferencia en una Escuela de Niñas de todas clases. Fueron exâminadas en la Doctrina Christiana y en la lectura, y presentaron sus labores de hilar algodon, medias hechas con sus mismos hilados, y otras obras de punto de aguja, trensillas y varios texidos, costura en blanco y bordado en bastidor; y aunque todas dieron pruebas de su aplicacion y aprovechamiento, fueron premiadas por mas sobresalientes dos con premio de á diez pesos, y seis con premios de á cinco, dividiéndose uno de estos entre dos por su igualdad de mérito (Gazeta de México, 15/4/1803: 1).

(21) Oracion que para abrir los Exâmens públicos de las Niñas que se educan en la Casa de Misericordia de la Ciudad de Cádiz, á presencia del Illmô. Señor Obispo, de la Junta de Gobierno, y del Pueblo que asistió, dixo en 24 de Marzo de este año Maria Dolores Lopez, una de las Educandas de dicha Casa.

Illmô. Señor $=$ Señores $=$ Aun no hemos olvidado el favor que merecimos en el año próximo pasado á V. S. Illmâ. y á V. SS asistiendo á los exâmenes, aprobando las muestras que dimos de nuestra aplicacion, y de que correspondimos al esmero de nuestros Diputados y Maestras, manifestandonos instruidas en las labores de hacer calzeta, coser, bordar, hacer encaxes, y tambien en leer, escribir, en los conocimientos de Ortografía y Gramática Castellana, y sobre todo en la Religion, de un modo que no son instruidas las mugeres, y mucho menos las pobres y desvalidas como nosotras (Gazeta de México, 13/9/1804: 3).

(22) Don Pedro Palacios, calificado de sobresaliente en todo el Catecismo comun, en la explicacion de la primera parte del de Soisons y 154 foxas del Compendio de Pinton; en la Ortología y Caligrafía, mediano en la Ortografia, y bueno en la Aritmética hasta multiplicar, fue premiado con la Gramática de la Lengua Castellana, la Clave geográfica del P. M. Flores y las Reglas de educacion añadidas... (Gazeta de México, 26/10/1804: 1). 
(23) Respondieron igualmente las preguntas que les hicieron de Aritmética, Ortografia, y Gramática castellana Luis Vicente Mairena, José Lalinde, Pedro Legorreta [..] (Gazeta de México, 24/1/1807: 13).

La enseñanza de la gramática, que se corporeizaba principalmente en los principios de lectura y escritura a través de la ortografía, constituía el primer objetivo de las escuelas, las cuales, progresivamente, fueron segregándose del poder eclesiástico y adhiriéndose cada vez más al control del Estado ${ }^{6}$. El proyecto ilustrado incentivó la creación de centros de enseñanza que pasaban ahora a ser supervisados por los gobernadores civiles. La Iglesia contaba ya poco en estos menesteres, pues la subvención procedería ahora de las Cajas de Comunidad después de las leyes de Intendencia, y estas se sometían también a un control estricto por parte de la Contaduría General de Propios y Arbitrios. La única manera que tenía la Iglesia a finales del siglo XVIII de intervenir en la educación fue mediante la fundación de las escuelas pías, de las cuales hay multitud de referencias en la prensa periódica:

(24) Razon de una Obra pia destinada únicamente á promover y adelantar la mejor educacion de la niñez en la Ciudad y Obispado de la Puebla de los Angeles.

Vencidas las primeras dificultades, que por desgracia padece siempre este género de obras, por calificadas que sean, se comenzó por la Escuela Real de primeras letras que mantiene el Seminario Tridentino Palafoxiano, anunciándose los primeros exámenes secretos, y distribucion de diez y seis premios á veinte y cinco reales (50 ps) en ropa, libros, ó dinero... (Gazeta de México, 26/10/1804: 1).

Un cambio en la política educativa del castellano, en donde los intereses por la enseñanza de la doctrina dejarían de estar ahora en el punto de mira, mejoraría las perspectivas de esta lengua en su avance hacia la consideración de lengua nacional. Con una Iglesia desplazada a un segundo plano y nunca preocupada por la castellanización, solo quedaba por resolver cómo atendería el Estado la situación lingüística de los primitivos pobladores de los territorios americanos. En esta labor de hacer que los súbditos de un pueblo entendieran el mensaje de los gobernantes, fue decisiva la intervención de la

6 Este control del Estado a través de la instrucción y la enseñanza de la lengua se hacía patente no solo por la incentivación de colegios de primeras letras, sino por la creación de instituciones como las "escuelas patrióticas" a partir de 1775, en las que se enseñaba a las mujeres a tejer e hilar, y a los hombres, a aprender otros oficios, además de la lectura y escritura (Magallanes Delgado 2011). 
prensa periódica, pues "el discurso escolar trascendía los muros de la escuela y se instalaba en las calles, en los mercados, en los centros de trabajo. Tras el uso reiterado de metáforas, fábulas, y ejemplos de la realidad, se justificaba y multiplicaba la exclusión y discriminación cotidiana" (Arredondo López 2011: 392). La Gazeta de México se encargó de crear entre sus páginas un ambiente propicio para la educación del pueblo, que escondía principalmente una llamada a la unificación lingüística desde las continuas referencias a las necesidades de saber leer y escribir:

(25) La Educación de la Juventud es uno de los mas principales ramos de la Policía y buen gobierno del Estado, que debe abrazarse y sostenerse por todos los individuos de una República, para felicitar á los hombres desde su primera edad, y sin unos principios sólidos no podrán conseguir felices fines. Los deseos de los Padres de familia, no son otros, que el devér logrados á sus hijos; pues su actividad y anhelo solo aspira á procurarles su aprovechamiento (Gazeta de México, 24/1/1792: 7).

\subsubsection{Periodo de 1810 a 1821}

En 1816, Fernández de Lizardi publica el Periquillo Sarniento, en donde queda reflejada, de manera satírica, en qué situación se encontraba el territorio respecto de la educación y de la enseñanza del castellano, una lengua sometida a crítica en España por su apego a lo francés. Lizardi opta por la defensa de un español normativo más cercano a los usos y costumbres de la metrópoli, y ante la crítica de algunos de los personajes a los que da voz en la publicación, que son más partidarios de la riqueza que aporta América en cuestiones lingüísticas. El periódico muestra a lo largo de sus páginas una reivindicación de la enseñanza en las clases más pobres y una condena al sistema educativo de los estamentos más privilegiados, que potenciaban sobre todo el estudio de la caligrafía y de la oratoria en latín. Era necesario que la educación fuese gratuita y obligatoria, impartida por profesionales competentes y bien pagados; además, Lizardi, en su "Testamento y despedida del Pensador mexicano", arguye el descuido de la situación indígena, que había caído en el olvido de los gobernantes:

Dejo a los indios en el mismo estado de civilización, libertad y felicidad a que los redujo la conquista, siendo lo más sensible la indiferencia con que los han visto los congresos, según puede calcular por las pocas y no muy interesantes sesiones en que se ha tratado sobre ellos desde el primer congreso (Fernández de Lizardi 1962: 46).

Con la llegada de Fernando VII, una Junta de Educación Pública y no los gremios debían examinar a los maestros, pero los virreyes leyeron tarde la 
regulación y, en la práctica, eran los ayuntamientos los que se encargaban de estas funciones. En el mismo año del comienzo de la insurgencia (1810), publicaciones periódicas como el Semanario de México hablaban de la importancia de ensalzar las virtudes de los maestros, que contribuían a preparar a los jóvenes para una vida mejor, y entre cuyas materias impartidas la enseñanza del castellano en sus más variadas disciplinas ocupaba un lugar especial:

(26) Y si esto es así ¿porqué en el Semanario no se ha de hacer la honorífica mencion que se merece el célebre y benemérito profesor de primeras letras D. Vicente Cayetano Martinez de Castro? La casualidad de haber asistido la mañana del 12 del presente mes à exâminar à un discipulo suyo D. Calixto Gomez, niño de 13 años de edad, me hizo conocer el mérito de este distinguido profesor. Despues de haber pronunciado el exâminando con mucho despejo y buena voz una eloqüente arenga (que original y del propio puño del niño acompaño à vd. para que se sirva insertarla igualmente si mereciere su calificacion) hecha por su maestro análoga à la funcion, satisfizo completamente delante de un lucido numeroso concurso à las muchas y no comunes preguntas que le hicieron, sobre doctrina cristiana, calografía, aritmética, gramática castellana, \&c. El maestro mayor de primeras letras D. Rafael Ximeno (quien absorto como yo y todos los circunstantes de la habilidad y despejo de aquel (Semanario de México, 30/8/1810: 279).

La Constitución de Apatzingán no llegó a avalar la enseñanza libre, pero sí advirtió de la importancia de la educación. La prensa se hacía eco de lo que debían aprender los niños en la escuela, en donde la gramática, ortografía y ortología del castellano constituían materias de primer orden:

EXÁMENES A LOS ALUMNOS DE:

Primeramente. De todo lo que pertenece al Culto Divino, con arreglo á los Catecismos de Ripalda, Pouget, Fleuri, y que como niños de Escuela deben saber \&c.

$2^{\circ}$. De todo aquello que pertenece á la urbanidad y buena crianza de los niños: como son reglas de cortesía, andar por la calle, comer en la mesa \&c.

$3^{\circ}$. De la Ortología, que enseña el conocimento de las letras, el sonido que tienen unas quando se juntan con otras, el oficio de las puntuaciones, el modo de leer, y quantas son sus reglas principales \&.

$4^{\circ}$. De la Calografía, que enseña el orígen y formacion de las letras, los trazos y raíces de que se componen el alto y ancho de cada una, la altura ó largo que tienen las letras, que suben ó baxan del renglon, la distancia 
que de una á otra ha de haber, y lo mismo de palabra á palabra, los cuerpos que tienen cada renglon \&.c.

$5^{\circ}$. De la Gramática castellana, que enseña el arte de hablar bien. Las partes principales que la componen y de las que ha de tratar: de cada una de las nueve partes de la oracion en particular: del artículo, sus accidentes y propiedades: del nombre, quantas especies hay de él, y conocimiento de cada uno: del pronombre, quantos son, y el oficio de cada uno: del verbo, quantas son sus divisiones tiempos, números, modos y personas: formacion de los tiempos: conjugacion de los verbos simples: idem de los compuestos: formacion de la voz pasiva: conjugacion de los verbos regulares é irregulares: conocimiento de unos y otros por sus radicales, y por su terminacion saber á que conjugacion pertenecen: quantas son las de los verbos castellanos, con sus demas accidentes y propiedades \&c. y así de las otras partes de la oracion: de la sintaxis en general: de la sintaxis regular: de la concordancia: del régimen de las partes de la oracion: de la construccion: de la sintaxis figurada: de las figuras de la construccion \&c.

$6^{\circ}$. De la Ortografia castellana, que enseña el arte de escribir con propiedad: del oficio y uso de las letras: de los caracteres españoles: de las letras de sonido equívoco, ó que se equivocan en la pronunciacion: de la concurrencia y órden de las letras; de las letras mayúsculas (NUEVA PÁGINA): de los acéntos: de varias notas para la pronunciacion: de la division de las voces y cláusulas: de algunas que suelen usarse en lo escrito: de las abreviaturas \&c. (Gazeta de México, 8/1/1815: 15).

De los exámenes en las escuelas daba cuenta la prensa, así como de los avances de los niños en asuntos de gramática y ortografía.

\subsubsection{Periodo de 1821 a 1830}

Poco antes de la declaración de Independencia, el 29 de junio de 1821, se publicaba un reglamento para que se declarase libre la enseñanza privada y para que las escuelas pías se equiparasen con las públicas. Dos años después, Iturbide solicita que se organice el sistema educativo con el lema "la letra con sangre entra", y en diciembre de este año se reglamenta un plan basado en leyes provenientes de España. En 1824, Jacobo Villaurrutia preparó el Proyecto de Reglamento General de Instrucción Pública, bajo cuyas normas se regulaba la enseñanza primaria, con clases de lectura, escritura, gramática castellana y ortografía. El texto distinguía las materias de primeras letras (leer, escribir y contar), necesarias para todos los estudiantes, y se agregaba otro grupo con aritmética y geometría práctica. Este proyecto fue avalado por José María Luis Mora, quien argüía la necesidad de un plan 
para enseñar a leer y escribir, exigido por los nuevos derechos democráticos de los ciudadanos ( $c f$. Báez Pinal 2009). A este reglamento le siguió el de 1826 - con el Plan de Educación Elemental, en donde también se enseñaría lectura, escritura y gramática-, el de 1827-Plan de Educación para el Distrito y Territorios, con la división entre enseñanza elemental o rudimentaria (religión, política y primeras letras)-, el de 1830 -o proyecto de Alamán, en donde se distribuye la instrucción por materias afines-, el de 1832 -Proyecto sobre Arreglo de la Instrucción Pública, en el que se pone de relieve la lectura y escritura, y se potencia la enseñanza a las niñas-, y el de 1833, con un currículo de primaria para niñas. Como afirma Heath (1972), entre las páginas del Diario de México, cofundado por Jacobo Villaurrutia, se dejan leer informaciones sobre la importancia de la instrucción para el refinamiento de las costumbres criollas - más orientadas hacia Europa, para ser precisos-y se incentivaba al aprendizaje de otros idiomas como el francés, considerado como "lengua viva universal", a la vez que se reservaba para el quinto curso la enseñanza del latín y el español. El modelo de castellano que se perseguía era el peninsular, como se deja leer en las siguientes palabras del "criollo mexicano" publicadas en el Diario de México:

(28) Qué gloria sería para la Nueva España igualarse en esta materia con la Metrópoli, y que resonara en sus distritos el agradable sonido de la verdadera lengua castellana, oyendo pronunciarla á los españoles americanos con toda la excelencia de que es susceptible, y dentro de muy pocos años, á lo menos en los que ahora empiezan a vivir (Heath 2011: 92).

La prensa periódica se encarga de la labor de recoger la opinión sobre la necesidad de una buena educación para el pueblo, llevada a cabo por buenos maestros, en donde las materias elementales siguen siendo las de lectura y escritura:

(29) Esta ciudad de Salvatierra y su ilustre ayuntamiento, ha tenido la suerte de estar careciendo de un preceptor de primeras letras en aptitud completa, para que se instruya la juventud, no solo en las artes novilisimas de leer, escribir y contar, sino tambien en los primeros rudimentos de politica y costumbres buenas (Águila mexicana, 12/5/1824: 3).

Los deseos para que los alumnos no solo se enfocasen en el castellano, sino también en otras "lenguas vivas" -en contraste paradójico a las indígenas, que empezaron a considerarse como clásicas-fueron plasmados en la prensa, después de que Villaurrutia avalara tales proyectos: 
(30) $4^{\circ}$ Los ramos que se enseñarán son los siguientes: escribir, siguiendo el plan de Mr. Rand; las lenguas española, inglesa y francesa, bajo un pan combinado, griego, latino, matemáticas puras y mistas, geografia, historia, dibujo y teneduría de libros... (El Nivel, 1/9/1825: 4).

Igualmente, se sucedían los escritos sarcásticos contra aquellos que no priorizaban las labores de la educación (sobre todo los padres de familia), la cual debería llegar no solo al sexo masculino, sino también al femenino, pues muchos peninsulares habían decidido quedarse entre criollos e indios:

(31) Por estas razones y otras que pudieramos añadir, por la edificacion de los fieles; y por el bien de sus almas, les prohibimos perpetuamente que lean ningun libro, bajo la pena de su condenacion eterna; y temiendo ademas que no les asalte el diabolico impulso de instruirse, prohibimos à los padres y à las madres de nuestros subidtos que enseñen ni hagan enseñar à leer à sus hijos ni hijas; proviniendo que para evitar toda contravencion à nuestro mandamiento, prohibimos espresamente, que piensen en cosa alguna que sea util, imponiéndoles sobre este punto las referidas penas; y ecsortamos à todos los verdaderos creyentes que denuncien à nuestros subalternos, à cualquiera que hubiese pronunciado o pronunciase cuatro frases unidas, de las que pueda inferir algo que tenga sentido comun. Ordenamos tambien que en todas las conversaciones se usen palabras que nada signifiquen, segun el uso antigüo de la sublime Puerta (El Nivel, 18/9/1825: 4).

A partir de aquí, la plasmación en los periódicos de los planes de estudios elaborados por el gobierno es constante. Se destacan las páginas de El Nivel (24/1/1826: 4) sobre el inicio de un plan de educación en el estado de Jalisco, en donde se advierte que este debe servir para hacer de los ciudadanos seres ilustrados y, así, no ser manipulados por torpes políticos: (34) "En ningun lugar es mas necesaria la ilustracion que en aquel en que los ciudadanos que lo habitan, tienen una parte inmediata en la accion del gobierno. Un pueblo ignorante elije para los supremos poderes hombres ignorantes y groseros; estos hombres sofocan las luces, y por un circulo inevitable, la falta de luces acarrea la esclavitud del pueblo". En este mismo número, se habla de la creación de un programa para escuelas y universidades, pues, nuevamente, la instrucción creará ciudadanos libres para elegir a sus mandatarios: "Pero hay otra ley constitucional que ecsije saber leer y escribir en el año de 1840 para entrar en el ejercicio de los derechos de ciudadania, la cual seria cruel é ilusoria en si misma, si al mismo tiempo no franquease por otra parte los medios de practicarla". Días despues, El Nivel (5/2/1826: 2) da a conocer el plan estatal para la educación de las niñas, que deberán saber leer, escribir y todo lo referente a su sexo: 
(32) De la educacion de las niñas

59. Se erijiran escuelas públicas para las niñas en todos los pueblos del estado.

60. En ellas se les enseñará á leer, escribir, contar, el dibujo y todas las labores convenientes à su secso.

61. Los fondos que se han de establecer estas escuelas, el nombramiento de los preceptores, y su dotacion, se igualaran en todo a lo dispuesto en este plan acerca de la primera clase de enseñanza.

En el Águila mexicana, se leen también artículos sobre instrucción pública y enseñanza de la gramática castellana y se ofrece información sobre establecimientos de educación, en cuyos artículos fundacionales consta en primer lugar la instrucción en lectura, caligrafía y gramática castellana, dejando para el final los fundamentos de la religión católica:

(33) Art. 1. Los alumnos son instruidos en la doctrina cristiana por los catecismos del padre Ripalda y Fleuri: se les enseña la lectura, caligrafia, gramatica castellana, aritmetica, elementos de geografia é historia y el dibujo (Águila mexicana, 29/8/1826: 2).

Y en el mes de diciembre (18/12/1826), este mismo periódico recoge la opinión de un articulista sobre el nuevo plan de instrucción pública presentado a la cámara de representantes, del cual se critica el escaso sueldo destinado a los maestros y la poca atención que se le ha prestado a la especialización de estos. Aun así, los ciudadanos siguen sin saber leer y escribir, motivo de queja de muchos editoriales, como el del Águila mexicana (29/9/1827: 3), que, en este caso, pone su objetivo sobre oficiales y soldados. La lengua y la gramática son igualmente objeto de discusión, materias estas que presentan un grado de dificultad incluso superior a las matemáticas, "porque de todas las ciencias son las matemáticas las que requieren para su aprendizaje menos caudal de ideas anteriores" (Águila mexicana, 19/10/1827: 3), y para el final -junto con el estudio de las bellas letras-, reserva el articulista el estudio de las lenguas:

(34) Despues de los estudios mencionados has aquí, entra bien el de las lenguas harto mas dificil que el de las ciencias. Solo la costumbre de enseñar estas en un idioma muerto, pudo hacer creer que la educacion literaria de la juventud debía comenzar por el aprendizaje del latin. El estudio de cualquier gramática requiere un fondo de conocimientos metafísicos de que absolutamente carece la niñéz: generalmente se agovia su memoria con un farrago de reglas que olvida de todo punto luego que deja de traquearla (ibidem: 3 ). 
La distribución federalista a la que llegaron los políticos en esta década dejaba la educación en manos de los diferentes estados, los cuales manifestaban ideas distintas de cómo enfrentar la instrucción de los ciudadanos. El Águila mexicana informa sobre los planes de instrucción del estado de Veracruz en su edición del 9 de septiembre de 1827, en donde se refleja el programa para la creación de diferentes institutos y para la difusión de las ciencias y de las artes, se aboga por la libre enseñanza y se potencia el aprendizaje de la gramática española según los principios de la Real Academia.

\subsection{Políticas EN TORNO A LA ENSEÑANZA DEL CASTELLANO EN LA POBLACIÓN INDÍGENA}

\subsubsection{Periodo de 1722 a 1810}

Quizá la intervención del Estado en los asuntos lingüísticos no hubiera sido tan insistente, si no fuera por la existencia de una gran variedad de lenguas habladas en su territorio, que hacían inviable la constitución de un imaginario colectivo homogéneo, el cual contribuiría, a su vez, a permitir un mayor control político de la población. Y de esta opinión es Anne Staples (2011: 356), quien nos advierte de lo siguiente: "La opinión pública reconoció la importancia de promover la educación indígena para lograr el proceso nacional. No era solamente para impulsar la modernización del Estado, sino para garantizar una población obediente a las leyes y consciente de sus deberes hacia la patria". Eran tres los obstáculos que retrasaban la tan ansiada homogeneización: 1. las lenguas indígenas y sus pobladores; 2 . la Iglesia, y 3. los criollos. Sin embargo, fueron estos dos últimos los que, paradójicamente, ponían más piedras en el camino a los deseos del Estado, pues ambos arrastraban intereses particulares en el proceso de unificación lingüística. Sin embargo, mientras la Iglesia veía necesario el proceso de endoculturación del indio desde la conversión al cristianismo, pues así se generaría una sociedad pacífica, a la Corona le interesaba más una estrategia de homogeneización lingüística, con el objeto de someter a estos pueblos al yugo de las leyes, pues en todo sistema de dominación, la vigilancia de los vencidos se atenúa con un pueblo controlado por la educación, en cuya base se asienta la lengua ( $c f$. Aguirre Beltrán 1993). No es de extrañar, pues, que la incentivación de la enseñanza del castellano fuera distinta en indios y criollos, hecho esto que queda ratificado por la evolución que presentan las designaciones de los centros de enseñanza: "escuelas de doctrinas", "escuelas de castellano", o "escuelas de primeras letras". Con el paso del tiempo, las escuelas de doctrinas, regentadas por frailes, fueron siendo 
sustituidas por escuelas de primeras letras y, según Tanck de Estrada (2000: 343), "para finales del siglo XVIII todo el mundo -los indios, los sacerdotes, los obispos y los subdelegados- distinguía claramente la diferencia entre las dos escuelas". Este cambio supuso igualmente una mudanza en lo físico, pues ahora, el nuevo lugar, la escuela, no estaría concebido exclusivamente para la enseñanza religiosa ${ }^{7}$.

En todo esto proceso de intervención política, los indios se mantuvieron como sujetos pasivos de la castellanización, pues el acceso al español estuvo condicionado en un primer momento por las escuelas de doctrinas, en donde adquirían la lengua de manera memorística (aprendían oraciones sin saber qué significaban) y, en muchas ocasiones, en latín. No obstante, después de que la Iglesia perdió sus prebendas, los indios -sobre todo los que pertenecían a la nobleza- realizaron muchas peticiones para que se abrieran escuelas con los fondos de la comunidad y no a través de los padres de familia, lo que albergaba los deseos de una población que no quería quedar marginada a causa de su imposibilidad de acceder a la política por el escaso dominio del castellano. Así, pues, existieron desde los primeros años instituciones de enseñanza planeadas para la población indígena, como el colegio superior de Tlatelolco, pero la nueva política pretendía castellanizar al indio tanto en los centros de pueblos con maestros de primeras letras, como en conventos y hospitales ( $c f$. Caso 1973). Y no hubo escuelas solo para niños, sino que se fundaron también otras tantas exclusivamente para niñas (las llamadas "migas" o "amigas"), en donde las chicas indias aprendieron no solo los rudimentos de lectura y escritura, sino también los de bordado y tejido ${ }^{8}$.

En los primeros años de la prensa colonial, puede rescatarse información sobre la educación indígena, cuya evolución va acorde con la política ya eclesiástica -en los años de influencia del clero-, ya gubernamental. Puede esperarse, pues, que los detalles sobre estos centros de enseñanza

7 Según nos indica Tanck de Estrada (2000: 207), "para los gobernantes de fines del siglo XVIII, "maestro de escuela" significaba preceptor de primeras letras, incluyendo la aritmética, asignatura no incluida en las reales cédulas sobre las escuelas de indios. Ya no se usaba el término "escuela de lengua castellana". A partir de la Ordenanza de Intendentes, se hablaba de educación en los lugares de españoles y en los de indios -en el artículo 34-, con las mismas palabras, "maestro de escuela", sin diferencia en el nombre de la institución ni en el enfoque o en las materias de enseñanza".

8 Estas escuelas para niñas no eran bien vistas por los padres, pues, dedicadas tradicionalmente las mujeres a labores de tejido, bordado y otros asuntos del hogar, se veía en el saber y escribir una amenaza contra progenitores y maridos, a los que podrían rebelarse con la instrucción (Tanck de Estrada 2000). 
evolucionaran desde una educación en lenguas vernáculas hasta la instauración exclusiva del castellano como lengua:

(35) La Provincia de los Santos Apostoles S. Pedro, y S. Pablo de Michoacán se erigió año de 1565, tiene diez y ocho Guardianias, y entre ellas dos Recolectas; un Colegio celebre en Zelaya, en que tambien Colegiales Indios; veinte Vicarias; diez y seis Assistencias; onze Conversiones en la Custodia de Rioverde; cinco Lecturas de Grammatica y Rhetorica; tres de Artes; Seis de Theologia Escolastica; una de Canones; ocho de Moral; una de la Mystica de la Venerable Madre Agreda; quatro de Lengua otomí y tarazca; diez y nueve Predicadores Conventuales... (Gaceta de México, 1/1/1735: 4).

A partir de 1780, la relación de noticias sobre la creación de colegios para indios, dedicados a enseñar a leer y escribir en castellano, es constante, e incluso se insiste en que estas poblaciones hablan ya castellano:

\section{SONORA}

El Apoderado de aquel Señor Illmô. avisa los vivos esfuerzos del zelo de este Prelado para llenar los deberes de su ministerio y las piadosas intenciones de S. M. (que Dios guarde), pues en el corto tiempo que ha que se cultiva aquel escabroso terreno ha establecido siete Escuelas de las primeras letras y dos de Gramática, con unos progresos tan rápidos, que el P. D. Joaquiín Valdés, Ministro de Doctrina y Rector, escribe á S. Illmâ. que ya los Indios hablan tan corriente el idioma Español, que dicen ellos: Ya todos somos Españoles (Gazeta de México, 5/7/1785: 3).

(37) El Colegio de Inditos Hiaquis, que se erigió en este Pueblo para primeras letras, segun se participó en la Gazeta de 5 de Julio de 85, despues de que sus primeros Alumnos aprendieron toda la doctrina Christiana, y á leer, escribir y contar, se abolió enteramente por falta de auxîlios para su subsistencia (Gazeta de México, 7/9/1790: 1).

Aunque muchos de estos colegios, en los que podían estudiar indios, admitían solo a los de apellidos nobles:

(38) 1. El Real Colegio de Nobles Américanos fundado por Mi en la ciudad de Granada tendrá por instituto dar á los jovenes naturales de mis dominios de las Indias Occidentales é Islas Filipinas una educacion civil y literaria, que los habilite á servir útilmente en la Iglesia, la Magistratura, la Milicia, y los empleos políticos.

2. Se admitirán como Colegiales los hijos y descendientes de puros Españoles Nobles, nacidos en las Indias, y los de Ministros Togados, 
Intendentes, y Oficiales Militares naturales de aquellos dominios, sin excluir los hijos de Caciques é Indios Nobles, ni los de mestizos Nobles, esto es, de Indio Noble y Española, ó de Español é Indio Noble, conforme al mérito y servicios particulares que sus padres hubieren hecho al Estado.

3. Para entrar en el Colegio los jóvenes han de tener la edad de doce á diez y ocho años, y han de venir instruidos en la gramática latina (Gazeta de México, 13/11/1792: 5).

Estas nuevas escuelas para indios presuponían que estos solo hablaban sus lenguas vernáculas, aunque la prensa se apresuraba en dar a conocer que sus estudiantes aprendían en corto espacio de tiempo a hablar, leer y escribir:

(39) [...] á la que [escuela] concurrieron muy gustosos los Inditos del Pueblo; y habiendo observado dos ó tres dias la Escuela de Inditas, solicitaron con empeño ser admitidas, lo que se les concedio con las precauciones necesarias para evitar todo peligro.

$\mathrm{Ni}$ unos ni otros sabian palabra en castellano; pero tomaron la cartilla con tal empeño, que se vieron luego unos progresos asombrosos; dentro del mismo año de 88 ofreció una muchacha la Comunion: una Indita llamada Maria Rosa Trinidad, tenia cinco años quando tomó la cartilla, y á los dos años ya leía latin perfectamente y cantaba en el coro (Gazeta de México, 4/10/1794: 3).

La prensa de la época estaba, pues, creando una opinión favorable en torno al indio con objeto de favorecer su integración. La estrategia ahora había cambiado: se anteponía el conocimiento del castellano a la labor de evangelización.

\subsubsection{Periodo de 1810 a 1821}

Con la Constitución de Cádiz, y a lo largo del siglo XIX, los gobernantes centraron su atención en la "civilización del indio" y en la unificación del territorio, por lo que la opinión en torno a este y su educación cambió respecto de los años anteriores, pues los esfuerzos políticos giraban en torno a la idea liberal de conseguir ciudadanos iguales ante la ley. Es así que, como nos advierte Flores Rodríguez (2012: 409-410), "la formación del indio fue vista como medio para lograr la unidad social y para fundar la soberanía nacional". Esta idea se quedó en un mero constructo de intenciones, ya que las guerras de independencia dejaron sin dinero las arcas públicas e hicieron inviables esos proyectos bien intencionados. Y un hecho tan ansiado como la abolición de la esclavitud y la devolución de los terrenos a la población -después de Hidalgo en 1810 - se volvía paradójicamente en contra de los 
más marginados, que debían ahora ocuparse de unas actividades económicas y políticas ignotas hasta entonces en estas comunidades. Al final, la educación progresó, como siempre, en las clases altas y a ser controlada por los frailes y clérigos, más interesados en los aspectos teológicos que en los lingüísticos. De resultas, la educación indígena, como afirma Ramírez Castañeda (2006), siempre estuvo orientada desde fuera por carecer de dinero e infraestructuras.

El 14 de mayo de 1817, Fernando VII dicta una Real Cédula para la creación de escuelas de primeras letras destinadas a los indios, aunque nada se decía sobre la castellanización, un proceso que no parecía interesar mucho al rey, habida cuenta de que la enseñanza y alfabetización se desarrollaba todavía en lenguas vernáculas. La prensa periódica se hacía eco de la importancia de la educación, pero no mencionaba el problema indio, pues este pueblo debía ser contemplado ahora como libre y con iguales derechos que el resto de conciudadanos. Sí es cierto que la opinión pública parecía interesarse más por que el indio supiese castellano, elemento clave para la unificación política; de aquí que existan frecuentes alusiones a las destrezas de estos habitantes en materia lingüística:

(40) $[. .$.$] pero que apenas estaban descansando de la lucha cuando se$ vieron cercados por mas de 300 bandidos que le hicieron un vivo fuego: que á pesar de verse ya con muy pocas jaras y ser inmenso el número de la maldita canalla que de refresco venia á la venganza de la primera, volvieron á ponerse en defensa los fieles indios, parapetandose en unas cercas de piedra que la suerte les proporcionó: que habiendoseles acabado las jaras fue tanta la chusma que cargó sobre ellos que aunque por algun rato le resistieron obstinadamente con garrotes y piedras, al fin los infames rebeldes lograron arrollarlos y dispersarlos, y que no obstante de verse vencidos los entusiasmados indios no cesaban de gritar los que sabian el idioma castellano viva el rey (Semanario de México: 2).

Estos deseos de hacer del indio un "ciudadano de razón", y que contribuiría a la unión de un territorio, pasaba por el tamiz de la lengua, pues sería esta la que lo elevaría a otra categoría cultural. La prensa advertía ya de cómo el indio se esforzaba en dominar el español, y se atrevía, incluso, a representar su forma peculiar de hablar, de la que reproducimos un pequeño fragmento:

\section{(41) El indio tulero contra el soñador mitífico}

On ladito, on ladito culicencia no lo tropelle algon persona, que lo llevo cargando los arco para el prusion que otro convento con sos monjita lo va à hacer on fiesta mas locida nuestra magre Santisma los Remedio: poro espera ostedes on poco que lo estoy cansado: lo sentaré tantito, é mientras te lo cuenta lo que goi lotro tarde que lo llevavvamos yo y mi 
compagre Don Pegro en el canon on pagresito, y otros dos caballero para que dan so vuelta por los chinampa de Santa Anita (Semanario de México, 19/7/1810: 233).

\subsubsection{Periodo de 1821 a 1830}

No habría resultado ser un acontecimiento celebrable la independencia mexicana para la población indígena, porque después de esta, el criollo la despreció por ignorante y por no estar metida de lleno en el mercado capitalista (v. Staples 2011). Además, el nuevo Estado se concebiría como un todo unitario en donde no tenía cabida un exceso de diversidad, tanto en costumbres como en lenguas. Las constituciones de Cádiz (1812), Apatzingán (1814) y el Plan de Iguala (1821) se adelantarían a conceder al indio su libertad, pero esta tenía un precio: el mayor control político de los nuevos ciudadanos a través de la renovación de las unidades administrativas. Así, el colegio de San Gregorio, tradicionalmente frecuentado por indios, pasará a ser visitado por criollos y mestizos, en donde la nueva educación, de carácter urbano, será impartida en español. Las distinciones raciales desaparecieron en lo administrativo, pero no en lo social y económico, pues se seguía hablando de indios y de "gente de razón"; la población indígena, tanto tiempo subsumida en sus costumbres, no tenía las destrezas suficientes como para adaptarse a las leyes de un libre mercado que desconocían. En lo que respecta a la planificación lingüística de la nueva nación, los gobernantes, según Heath (2011: 13), "se convirtieron en programadores cuyas decisiones se basaban en planes de integración por realizar para que la población indígena efectuase su transición social y económica a la vida moderna. Además, esas decisiones exigían la participación directa y activa de agentes locales de cambio, encargados de que se cumpliera la política lingüística". No interesa ya crear un aula específica para enseñar al indio, pues este era igual al resto. Este hecho se convirtió en motivo de debate político en 1824 entre Juan de Dios Rodríguez Puebla, abogado de origen indígena, y Luis de Mora, quien pensaba que no había que hacerse distinción alguna entre los distintos pobladores. Las quejas sobre la educación indígena continuaron en años sucesivos sin llegarse a un acuerdo, pues los gobernantes contemplaban a los indios como un reducto cultural solo salvable desde el punto de vista histórico.

Los escritos en la prensa periódica recordaban a la opinión pública que el indio no reunía las condiciones para la integración como ciudadanos, pues aún no dominaban el español. Los frailes, por su parte, seguían empeñados en una evangelización sin objetivos castellanizantes: 
(42) Se oponian [los frailes] tambien abiertamente á que se les diese instruccion, pero contrariando su opinion se han puesto dos escuelas de primeras letras, una en Loreto y otra en el Real de S. Antonio, y los adelantos son visibles, porque los talentos de estos hombres son muy claros. En su estatura son perfectos, robustos, membrudos y corpulentos. Los indígenas pronuncian el castellano tan claro como nosotros... (Águila mexicana, 30/5/1826: 4).

(43) [...] el 4 de agosto de cada año se celebra una fiesta muy grande, á la que siempre vienen indios lacandones mansos; no hablan castellano, y segun dicen, lengua maya de Yucatán (Águila mexicana, 13/7/1826: 4).

En definitiva, la educación del indio en la lengua se contemplaba como necesaria para luchar contra sus conquistadores, aunque sería útil que hablaran castellano, incluso se admite que lo hagan -como parece que así identifican su hablar- "a la andaluza":

(44) Los generosos valientes americanos, se han visto en obligacion de tomar las armas contra los españoles, verse libres de ellos y de su odioso gobierno; ellos al combatirlos no fueron en busca de laureles, pretendieron esterminarlos, y lo consiguieron: han querido botarlos de la América, pero por compasion han quedado algunos que han procurádo dar á conocer que son hombres pacificos y racionales: de lo contrario, ya en todo el nuevo mundo no se oyera hablar á la andaluza, lo que tal vez fuera muy útil, y nos evitaria tener cargados con las armas brazos que pudieran dedicarse al cultivo de la tierra, ó otros oficios de que pudiera resultar mayor provecho á las repúblicas (Águila mexicana, 9/7/1826: 4).

\subsection{TRANSMISIÓN GRAMATICAL: MÉTODOS Y MANUALES}

\subsubsection{Periodo de 1722 a 1810}

La creación y difusión de manuales y métodos de enseñanza de la lengua esconden en sí mismos una política lingüística subrepticia de los gobiernos, pues estos constituyeron, en cierto modo, una manera de obligar a acceder a determinados conocimientos desde un molde gubernamental. Inconscientemente para la población, aunque bien pensado por los gobiernos, el libro de texto (ya fuera en forma de cartilla, catecismo o catón) contenía los elementos necesarios para reconducir al estudiante por la vereda de las leyes (v. Báez Pinal 2009). La prensa ejerció el papel de transmisor subliminal, pues entre sus páginas se podían leer discusiones sobre los mejores métodos para aprender a leer y escribir, así como los textos y manuales más apropiados 
para el estudio. Una simple mención de las gramáticas que se escribían en el territorio o que provenían de España era suficiente para adoctrinar a los lectores sobre las formas más convenientes de asimilar la norma del castellano. En este sentido, se podría hablar con MacKenzie (2002) de una auténtica "sociología de los textos", es decir, los condicionantes que facilitaron su publicación y difusión, pues sus significados no son inherentes, sino que se "construyen mediante sucesivos actos de interpretación de aquellos que escriben, diseñan e imprimen libros, y de aquellos que los compran y los leen" (Garone Gravier 2014: 236).

Durante los primeros años de la Colonia, se escribieron muchas gramáticas sobre lenguas indígenas, pero, curiosamente, estas iban destinadas no a estudiantes indios, sino a españoles (fundamentalmente frailes). La alocución nebrixense de que la lengua debía ser compañera del imperio no encontraba en el castellano una fácil cristalización, pues, a diferencia del Imperio Romano, el Nuevo Mundo ofrecía un panorama radicalmente distinto, con vehículos de comunicación basados en sistemas ignotos. A fray Pedro de Gante se le atribuye la primera cartilla para enseñar a leer en 1569 , pero a partir de 1591 se usó el catecismo de Ripalda, construido en forma de diálogos, para el adiestramiento en los menesteres de lectura con intenciones también adoctrinantes, aunque previamente el alumno debería ser instruido en las nociones de la letra. Así pues, tras pasar por la cartilla (con el método de deletreo) se llegaba al catón, de contenido religioso. A finales del siglo XVIII, no obstante, comenzaron a manifestarse los detractores del sistema de deletreo en favor del silabeo y fue en 1780 cuando Antonio Cortés publica un manual similar a una cartilla, aunque considerando la sílaba en vez de la letra (silabario), y en donde se reproducían sílabas, diptongos y oraciones religiosas. En 1786, Francisco Xavier de Santiago Palomares reforma la enseñanza de la escritura y lectura a través de su manual El maestro de leer. Conversaciones ontológicas y nuevas cartillas para la verdadera y uniforme enseñanza de las primeras letras. Y en los inicios del siglo XIX, se adopta definitivamente el silabeo como método de enseñanza tras la publicación del Nuevo arte de enseñar a leer (1824), de Torres Naharro. Téngase en cuenta, además, como detalle sobre la recepción de estos métodos, que las prácticas pedagógicas se enfocaban fundamentalmente sobre una población que solo quería aprender a leer, y no tanto a escribir, entre otras cosas, porque la destreza escritural exigía el uso de papel importado, el cual era escaso y caro.

A este respecto, las noticias de los primeros periódicos se dedicaban a informar sobre el uso de estas cartillas para aprender a leer en la población indígena, pues con estas destrezas se lograría civilizar a estos "seres irracionales": 
(45) [...] y se están cathequizando los restantes, en quatro Missiones de los Padres de la Compañia, á que se reducen todos los Pueblos, en que se han congregado los Naturales, y están de modo pacificos, y sujetos á la direccion de los Padres, que se les han remitido algunas gruesas de Cartillas, para enseñarlos á leer, y tan pacificos y dociles, que parece, que de muchos años antes professaban la Politica, y exercitan las costumbres de racionales (Gaceta de México, 10/4/1722: 992).

En este mismo año, se publica otra noticia sobre California y su nuevo puerto, en donde se deja leer una descalificación al oficio de gramático, que en la época $-\mathrm{y}$ confundido con la denominación de literato- se identificaba con un arte confuso, abstracto y de poco valor. Esta percepción, reflejada no solo en la prensa, sino también en la literatura ( $c f$. Rivas Zancarrón 2017b) tiene una gran importancia sobre la recepción y difusión de los manuales de enseñanza, pues las indicaciones gramaticales (fundamentalmente ortográficas) se basarán en los textos creados por maestros de primeras letras. Este detalle merecería ser estudiado para valorar la importancia de la difusión de las ideas gramaticales:

(46) Y a mi corto juicio estas ommissiones a vista de otras cosas muy inutiles pueden causar desprecio enla censura politica alos futuros Anales, pues no siendo inferior el desvelo, conque Pydimo insigne, escudriñador delos antiguos compuso quatro mil volumenes inquiriendo en todos la verdad sus mesmos panegyristas (no poniendo defecto en lo puntual, y verdadero) calumnian de vanas y futiles sus obras (4). Sino es, que merescan esta calificacion, porque su autor solo fue de profession Grammatico. Pero las Gazetas logran enel celebradissimo sujeto, que las trabaja, un Hombre sabio in Vtroque (Gaceta de México, 13/6/1722: 1119).

La información que ofrece la prensa sobre estos manuales y métodos experimentaría, naturalmente, una evolución acorde con los cambios políticosociales de la Nueva España, en donde se observa la progresiva decadencia de la influencia eclesiástica en la enseñanza de la lengua: desde referencias a textos en lenguas indígenas, hasta información sobre manuales escritos en latín y, posteriormente, en castellano. En 1728, se informa sobre libros gramaticales que se han introducido en el territorio como el Compendio de Instituciones Grammaticales de Manuel de Santa Theresa (Gaceta de México, 1/3/1728: 7); en 1732, se registra el Vocabulario en lengua castellana y cora, escrito por Joseph de Ortega (Gaceta de México, 1/8/1732: 8); en 1734, se lee información sobre el Artificiosum Vocabularium Poeticum, seu Prosodicum, \&c. dividido en una Manuduccion de siete Centurias, y en veinte y ocho Vocabularios curiosos... (Gaceta de México, 1/11/1734: 8) 
para la enseñanza del latín; en 1737, comienzan a introducirse noticias sobre manuales ortográficos como el Tratado de Buen escribiry de la Orthographia Perfecta de Juan Palafox Mendoza (Gaceta de México, 1/11/1737: 3); en 1738, se reseña el Arte de la lengua japona de Melchor Oyanguren de Santa Inés (Gaceta de México, 1/3/1738: 8), compuesto según el arte de Nebrija, y muy interesante, pues aquellas pronunciaciones que no pueden solventarse por el alfabeto latino se adaptan desde las lenguas amerindias, y un largo etcétera. Desde las reseñas de estas publicaciones puede observarse la evolución que experimenta el calado de las ideas gramaticales en la sociedad: desde trabajos sobre lenguas indígenas, hasta aquellos que reflejan ya contrastes entre el castellano y algún que otro idioma prehispánico, para acabar en los estudios exclusivos sobre el español. Igualmente, la influencia de Nebrija comienza a desaparecer en el último tercio del siglo XVIII, sobre todo después de que Carlos III fomentara la enseñanza por otras artes. Serán los textos escritos por maestros y no los reflejados en compendios gramaticales más abstractos los que triunfen en las decisiones políticas $\mathrm{y}$, consecuentemente, en la opinión pública. Las referencias a este tipo de textos son numerosísimas:

(47) El Excmô. Señor Virey de este Reyno, por su Superior Decreto de 16 de Agosto de este año, há concedido Privilegio exclusivo á D. Rafael Ximeno, Maestro mayor de las Nobiilísimas Artes de primeras Letras, para la impresion de un Quaderno de Reglas de Ortografia, muy util para la instruccion de los Niños en la escritura: se vende al precio de 2. rs. en su Escuela Real y pública, calle de la Monterilla (Gazeta de México, 19/10/1790: 7).

(48) En esta Ciudad de Veracruz, y en la Librería de Don Manuel Lopez de Luna, se vende una nueva Cartilla para enseñar á leer los niños, cuyo título es: Silavario metódico, ortolójico y ortográfico, dispuesto por un aficionado al Magisterio. Es la mejor produccion que en su clase ha salido hasta ahora á la luz pública, pues los niños con solo conocer las letras del Alfabeto, hallándose en estado de no equivocar ninguna, en el corto tiempo de diez dias, los mas lerdos, aprenden toda la parte primera del Silavario, y emprenden la lectura de qualquiera Libro sin aquel trabajo penoso del deletreo, que tanto los molesta sin adelantar ni progresar sino á fuerza de meses y años (Gazeta de México, 23/10/1789: 1).

(49) Don Joseph Mariano Palafox sobre este ramo y el Catecismo corriente, escribirá de delgado y multiplicará; y será exâminado en el Catecismo histórico de los niños del célebre Abada Fleuri, así en las lecciones como en los diálogos; y en la Ortografia del V. Sr. Palafox (Gazeta de México, 26/10/1804: 1). 
(50) No sabemos aún las providencias que toma S. Illmâ. para organizar el establecimiento; y así solo diremos de los Impresos que se han dado á luz. Son en un volumen corto de 144 llanas las Reglas de la buena crianza, la Ortografia del V. Señor Palafox, un Epítome en diálogo de la Gramática de la Lengua Castellana, y unas ligerisimas nociones de Aritmética (Gazeta de México, 16/10/1804: 4).

Con la supresión progresiva del gremio de maestros, la prensa se hace eco de la creación de escuelas y de sistemas pedagógicos especiales desarrollados por instructores particulares, que enseñarían sobre todo los rudimentos de lectura, escritura y ortografía:

(51) Este nuevo método es el mas fácil, útil, y provechoso para que los niños aprendan á escribir con brevedad; pues estando bien templada la pluma, y explicándoles como la deben manejar, sacarle los trazos, y colocar el brazo sobre la mesa, indispensablemente formarán todas las letras minúsculas de nuestro Abecedario [...]. Tambien los instruirá en los dogmas de la Religion, máximas de educacion, puntos de Ortologia, Calografia y Ortografia, y no omitirá todo quanto sea conducente para formar un hombre verdaderamente Christiano, civilizado en las mas loables costumbres (Gazeta de México, 21/10/1794: 11).

El proyecto ilustrado se dejaba leer en la prensa, pues este consideraba que el saber leer y escribir eran destrezas fundamentales para acceder al conocimiento y hacer más libres a los individuos. Los métodos de enseñanza dejarían a un lado el castigo físico y se incentivaría al alumno con premios, amenaza y ejemplo:

(52) El saber leer, escribir y contar es tan necesario para la humanidad, que, sin estas artes, fuera una confusion el Universo, y en muy poco se diferenciaria la vida de los hombres de la de los irracionales.

Estas Artes, que son el principio y fundamento de todas las Ciencias, es indispensable prenderlas con perfeccion, y abrazarlas con dulzura, para llegar á la cumbre de conseguir las demas. Comienzan á aprenderlas los hombres desde su primera edad, en cuyos tiernos años, sin conocimiento alguno, solo apetecen y se inclinan á la diversion, al juguete y entretenimiento.

Los padres de familia, con aquellos naturales y nobles pensamientos que les asisten, desean la educacion de sus hijos, y les solicitan Maestros que los instruyan. Estos, por lo general, se han valido del rigor y castigo de los azotes para conseguir el adelantamiento de sus Discipulos, obscureciendoseles hasta ahora nuevos métodos ó arbitrios con que 
establecer una enseñanza sin rigor y sin castigo (Gazeta de México, 23/11/1790: 11).

Y estos métodos los explica con rigor la prensa periódica en algunos de sus números, en donde la figura del "maestro mayor" se consolida para la creación y supervisión de cartillas o, incluso, para el otorgamiento de las licencias para enseñar:

(53) La Educacion de la Juventud es uno de los mas principales ramos de la Policía y buen gobierno del Estado, que debe abrazarse y sostenerse por todos los individuos de una Republica, para felicitar á los hombres desde su primera edad, y sin unos principios sólidos no podrán conseguir felices fines $[\ldots]$.

Hasta el presente tiempo se ha carecido en ellas de unas reglas, ó método fixo, que enseñe é instruya á la juventud en las principales artes y reglas que deben civilizarla, pues los mas de los Maestros han seguido un método torpe, sin discurrir reglas ni arbitrios con que adelantar á sus Discípulos para su mayor utilidad.

Esta consideracion, el patriótico amor, y la experiencia que ha adquirido en el dilatado tiempo que se ha exercitado Don Rafael Ximeno, Maestro mayor por S. M. (que Dios guarde) de las Ilustres Artes de primeras letras, en educar á la juventud, le ha hecho dedicarse á discurrir y buscar las mas sólidas reglas y maxîmas de educacion para la enseñanza de sus Discipulos, que manifestará al Publico experimentando su adelantamiento. Y aunque pudiera reservar para su Escuela el método que ha de observar, lo manifiesta la público para su inteligencia.

Asintanlo por principio que el buen Profesor debe valerse mas de los arbitrios y el arte para la enseñanza, que del rigor y la disciplina, priva enteramente en su Escuela el azote, y en ella sin este antiguo, y odioso modo que lo sirve y ha servido de infundir temor á los Niños, y de abrazar las artes con horror, promete enseñar con el mayor esmero y perfeccion las reglas de leer, escribir y contar.

Para conseguirlo (en el mejor modo que ha podido) tiene formado un Arte de leer compuesto de la mayor parte de sílabas y Nombres de nuestra [sic] Diccionario Castellano; un Arte de escribir, que en siete Pautas y veinte Muestras dá la idea de aprender otras tantas formas de letras, sacadas de los mejores Autores; un Arte de contar, que con la mayor claridad, no solo contiene las quatro reglas, sino que enseña todas las reglas y cuentas que son utiles en este Reyno para una instruccion perfecta; cuyas obras no han salido á luz, por los crecidos costos que tiene el abrir sus láminas y su impresion $[\ldots]$. 
Despues repasarán las Oraciones del Catecismo, la Tabla, y las reglas de Ortografía: y por las tardes la declaracion de la Doctrina Christiana que se les señalare, y el modo de ayudar â Misa Romano y Griego [...].

Luego que cesen de escribir, tomarán todos sus Quadernos de Ortografia, y lo irán repasando en voz alta conforme se les mandáre, cuyo exercicio los soltará en la lectura, y les hará aprender de memoria estas tan utiles reglas (Gazeta de México, 21/1/1792: 7).

Finalmente, la fuente que regirá la norma del castellano será siempre la de la Real Academia Española, a la que consultarán los maestros para fundamentar sus teorías pedagógicas y sobre cuya norma sustentarán sus enseñanzas. Igualmente, la obra lexicográfica de consulta será también el Diccionario de esta institución académica:

(54) Ya veo que un Discípulo poco conocimiento puede tener de las producciones que son aqui indigenas, y en caridad para que en otra ocasion no dé un tropezon con un tronco por falta de advertencia, le aconsejo ocurra al Sabio Diccionario de nuestra Academia Española, allí leera lo que es Tronco, el que se define así: “Tronco: La parte inferior de los Arboles y Plantas, dura y sólida desde el suelo hasta donde se divide en Ramas" (Gazeta de México, 15/7/1788: 10).

\subsubsection{Periodo de 1810 a 1821}

En los años que abarcan este periodo, la preocupación política fue mayor a la de la creación de un ambiente propicio en las escuelas por el que se enseñara un español de acuerdo con una norma, unas ideas y unos métodos. Durante el siglo XVIII, las clases altas de la sociedad americana habían dirigido su mirada hacia el castellano peninsular, pues identificaban en sus usos discursivos y manera de hablar un resabio de civilización y buenas costumbres. Esta mirada propiciaba un seguimiento escrupuloso de los dictados gramaticales de la Real Academia, institución que nunca consideró el aporte a la lengua de estos pueblos, al menos en el lado de la gramática. El otorgamiento de los privilegios de ciudadano a todos los habitantes de América después de las Cortes de Cádiz planteaba una enseñanza de la gramática todavía más pragmática, pues el derecho a votar pasaba por saber leer (no tanto escribir). Y así, frente a la dificultad de la creación de nuevas escuelas por la falta de dinero, el objetivo principal de la educación se centró en enseñar tres destrezas básicas: leer, escribir y contar. En este sentido, salvo algunas referencias a la introducción de diccionarios (como el de latín y castellano de Valbuena en la Gazeta de México de 26 de septiembre de 1815), pocos reflejos existen en la prensa sobre cómo debía aprenderse el español, ya que, 
nuevamente, las abstracciones de los gramáticos eran vistas como inútiles ante unos objetivos tan primarios como la alfabetización de un territorio. En definitiva, el estudio concienzudo de la gramática era visto como un lujo innecesario:

(55) En cuanto à no saber gramática, le confieso con la ingenuidad que acostumbro que ciertamente no he pasado decenas de años en algun colegio aprendiendo generos, pertèritos, notas, divisiones de términos; proposiciones modales, exponibles, exeptivas, reduplicativas, suposiciones, apelaciones \&c. y otras como estas que de nada sirven dice Feijo; (teatro critico 7, Disc. 11) pero tampoco he tenido trabajo de olvidar muchas de estas cosas para poder discurrir con acierto, y expresarme con alguna propiedad y claridad [...] (Clamores de la fidelidad, 25/4/1814: 104).

En este periodo, y para facilitar la unificación política, se incentivó la enseñanza del español a los indios, a la vez que las lenguas vernáculas comenzaron a sufrir un progresivo silenciamiento, pese a su presencia en las escuelas. Los métodos para enseñar español, fundamentalmente destinado a los indios, ocultaban la otra realidad: la relegación de las hablas indígenas al bagaje cultural de una nación, a su historia y no a su presente.

\subsubsection{Periodo de 1821 a 1830}

La situación sociopolítica del nuevo Estado, que consideraba prioritaria la educación de sus ciudadanos, modeló también la transmisión de los métodos y manuales que debían seguirse para la instrucción de los estudiantes. Estos libros de texto constituían, según Arredondo López (2011), una manera de construir la intolerancia en la escuela, en donde se servían de tres tipos de materiales: el Catecismo de la doctrina cristiana de Ripalda (para la enseñanza religiosa y las buenas costumbres), los Diálogos de Juan Luis Vives (que instruía sobre los derechos civiles) y el Catecismo de la República (que ayudaría al nuevo ciudadano a comportarse adecuadamente en la vida pública y política). Con todos los derechos civiles restablecidos y con las intenciones de hacer cumplir las leyes de manera democrática, el Estado se topó siempre con dificultades económicas que obstaculizarían el cumplimiento de los deseos políticos. Las nuevas propuestas de escolarización necesitaban dinero y este acabaría obteniéndose finalmente de los bolsillos particulares de las familias. No obstante, por aquella época, triunfaba un sistema de enseñanza que, por sus características metodológicas, reducía considerablemente el presupuesto para maestros, pues garantizaba 
una escuela con multitud de alumnos y un solo docente oficial: para que el adiestramiento llegara adecuadamente a todos los estudiantes, se elegían preceptores entre los más aventajados. Se trataba del sistema lancasteriano, del que la prensa del momento se encargaría de encumbrar y crear una opinión favorable. El 22 de febrero de 1822 llega a México la compañía lancasteriana con la intención de promover escuelas gratuitas favorecidas por las bondades del método que desarrollaban. La escuela "El Sol" fue el primer local de enseñanza autorizado por Iturbide para la impartición del método mutuo de Joseph Lancaster y Andrew Bell, y bajo la supervisión de sus fundadores (Manuel Codorniu, Agustín Buenrostro, Eulogio Villaurrutia, Manuel Fernández y Eduardo Torreu). Dos años más tarde, en 1824, la compañía publica una cartilla con el título Sistema de enseñanza mutua, para las escuelas de primeras letras de los estados de la República megicana, por la compañia lancasteriana, en donde se proponía, además del uso de preceptores elegidos entre los alumnos más aventajados, simultanear la enseñanza de la lectura y escritura. Posteriormente, en 1828, el Estado de Occidente ordenaría el establecimiento de escuelas de primeras letras siguiendo también el sistema lancasteriano, y en 1833 el presidente Gómez Farías ordenaría definitivamente el uso de este método para las escuelas que se fueran creando en México.

Entretanto, el fraile chiapaneco Matías de Córdova publicaba en $1825 \mathrm{su}$ nuevo sistema de enseñanza primaria, con el objetivo de tratar por igual en el aspecto educativo a indígenas y ladinos, lo cual se conseguiría con el "método fonético": priorizar el conocimiento de la letra por su sonido, figura, uso y combinación, para, así, mediante el silabeo, adiestrar más rápidamente en la enseñanza de la escritura y lectura. Este sistema fue perfeccionado luego por fray Víctor María de Flores con su Método doméstico y experimentado para enseñar a leer y escribir en 62 lecciones (1840).

La prensa periódica se llena de comentarios sobre las nuevas cátedras de gramática castellana que se convocan (Águila mexicana, 4/3/1821: 141; Águila mexicana, 19/11/1826: 3, y un largo etcétera) y se reseñan textos gramaticales y ortográficos necesarios para el aprendizaje del español (Iris de Jalisco, 21/7/1824: 4, con menciones sobre venta de gramáticas y ortografías, o el Iris de Jalisco, 27/9/1824: 4, en donde se hace referencia al diccionario bilingüe francés-español de Gattel). Entre estos, mención especial merece la descripción del tratado de ortografía de Ontiveros, en donde se hacen apreciaciones sobre las últimas reformas ortográficas de la Real Academia (1815): 
(56) Ortografia

Ultimamente se ha impreso en la oficina de Ontiveros un pequeño cuaderno titulado compendio de ortografia en verso castellano, adoptado últimamente para mayor inteligencia de la juventud. Como no tenemos quien nos ayude en nuestras ocupaciones, no hemos tenido lugar de leer con detencion este cuadernito: nos hemos contentado con quebrantarlo, ojeándole rápidamente; pero esto ha sido bastante para conocer que su autor, sea americano ó español, está regularmente versado en los elementos de la lengua castellana, pues su doctrina es opuesta á los vicios de ortografía que comunmente observamos.

En cuanto al uso de la $\mathrm{x}$ todavía vemos que la conserma en las voces exámen, exequias, \&.c. cuando es asi que ya se usa con generalidad de su equivalente $c s$; pero este modo de opinar no se puede calificar como un defecto (Águila mexicana, 24/10/1825: 1).

Los nuevos textos reivindican otros métodos y distintas concepciones. Así, la gramática de Nebrija pierde su actualidad y se exigen otras artes para acceder al conocimiento de la lengua latina y de la castellana:

(57) $[\ldots]$ conociendo los defectos del arte que se llama de Nebrija, demostrados desde mucho tiempo en diversos escritores, y acreditados por la esperiencia de muchos años: no habiendolos de igual clase en el nuevo método para estudiar la lengua latina que se publicó en Francia para el uso de los Licéos, y escuelas secundarias; y deseoso de dar á las clases de gramática la perfeccion posible en su actual estado, ha acordado: $1^{\circ}$ que una comision compuesta de los CC. José Francisco Barrundia, Manuel Valero, y Manuel Arbeu se ocupen de traducir dicho nuevo método suprimiendo las declinaciones, conjugaciones \&c. de la lengua francesa, substituyendo en su lugar las de la lengua española, y añadiendo las notas mas convenientes para su mayor claridad y perfeccion: $2^{\circ}$. que evacuado este trabajo con el celo que debe esperarse de la comision se publique, abriendo subscripcion para no gravar á los fondos públicos, y se circule á todoas las clases de gramática para que se arregle la enseñanza simultanea de los idomas latino y castellano á un método que promete ventajas en la de una y otra lengua (Águila mexicana, 12/8/1824: 3).

Aunque el latín se relega ahora a un segundo plano, frente al español: "Mejor sería que aprendieran a hablar el castellano medianamente al latín". (El Invitador, 24/11/1826: 3). No faltaron tampoco quienes, desde el poder, aprovecharon para reivindicar distintos planteamientos ortográficos a los de la Real Academia, como los formulados por Jacobo de Villaurrutia, conocido 
heterógrafo. Este llegó a enfrentarse incluso a Carlos IV por sus usos gráficos en un periódico que fundó en los primeros años del siglo XIX. En el siguiente fragmento, La Águila mexicana publica un texto de este autor, quien pide que se respete su grafía, muy parecida a la que propondrán autores como Bello:

(58) Sres. Editores. Siento mucho qe en un periodico de tanto crédito como la Aguila mejicana, ayan VV. echado un lunar, como el comunicado del núm. 227 en qe por onrarme el autor, ofende á dos Sres. majistrados, qe aunqe no fuera por sus buenos servizios, por solo la autoridad en qe estan constituidos, merecen toda atencion y respeto, y mucho mas cuando à nadie ofenden con azer presente á la suprema autoridad las razones, qe creen favorezer su solizitud. Yo sentiré siempre qe por mi se agravie al ultimo de los ziudadanos: y ya que no tiene remedio la publicazion, tengan VV. la bondad de insertar estas cuatro palabras. Mientras no se respeten las personas de los qe ejerzen la autoridad publica en cualqiera de sus ramos, no puede aber buen órden en la soziedad sin qe esto impida la justa libertad de imprenta para manifestar los erróres. B. 1. m. de VV. su atento servidor Jacobo de Villaurrutia (Águila mexicana, 30/11/1823: 2).

Las publicaciones sobre el método lancasteriano se suceden ya desde 1822, como el texto aparecido en La Sabatina (28/9/1822: 4), en donde se explica con claridad cómo se lleva a la práctica este sistema de enseñanza, que llevaba implícito una mejora del desarrollo lingüístico en español, pues esta lengua se concebía como necesaria para la vida pública. A lo largo de las páginas de esta edición de La Sabatina se explica al detalle cómo funciona el método lancasteriano y de qué forma ha de enseñarse a leer y escribir, mediante la combinación de las distintas letras del alfabeto.

Y si hay una gramática que se seguirá especialmente en los distintos programas, esa será la de la Real Academia Española:

(59) 10. La gramática castellana se enseñará por la gramática llamada de la academia española: la gramática y tradicion del idioma latino por Orellana: la enseñanza de entrambos idiomas no podra durar mas de uno y medio año.

11. La enseñanza de la traduccion y pronunciacion del idioma frances y del ingles, se hará por los autores que elija el profesor: la enseñanza del primero de estos idiomas durara seis meses; la del segundo un año (Águila mexicana, 9/11/1827: 3).

En este fragmento, es curioso cómo la enseñanza del español no tiene otro texto que el de la Academia, frente a la del francés o inglés, en donde se da vía libre al maestro para su elección. 


\section{CONCLUSIONES}

El ser humano se organiza socialmente a través de la política, y la lengua adquiere su sentido de ser en lo social. Siendo esto así no nos resultaría extraño adivinar cómo una organización política puede ejercer sus influencias sobre el vehículo comunicativo que sustenta una comunidad de personas. Es cierto que la lengua es un organismo autónomo en el significar, pero los significados particulares de su sistema pueden variar en el momento del designar, esto es, en la operación de exponer sus fórmulas de funcionamiento en la situación y circunstancia particular de un acto de hablar concreto. Le toca al investigador la labor de descubrir cómo con la variación de los sistemas políticos, que estructuran los esquemas de una sociedad, puede llegarse a perfilar el sentido de una mudanza lingüística, o, quizá, a explicar el porqué de las diferencias entre determinados dialectos y formas de hablar. El trabajo de pesquisa se complica si no tenemos testigos del hablar, es decir, si el análisis lo centramos en un estado de lengua anterior y, por tanto, desconocido; por esto, el objetivo de nuestra investigación -ofrecer un perfil de la posible intervención política en los destinos del español durante los últimos años de la Nueva España y los primeros del México independienteno ha tenido más remedio que recurrir al texto escrito. Además, hemos querido servirnos de un tipo textual, la prensa periódica, que, a su vez, por sus características de inmediatez en la transmisión de las ideas, pudo haber ejercido una influencia sobre los designios del castellano en sentido biunívoco: o convertirse en irradiación de las repercusiones sobre lo político o servir de instrumento para la creación de una opinión pública en torno a la lengua. En el caso concreto que nos ha ocupado, los escritos periodísticos han ayudado a construir una fotografía dinámica sobre cómo han influido sobre la lengua los diferentes acontecimientos políticos. A partir de la prensa periódica, y ya desde las primeras publicaciones en 1722, se pueden llegar a corolarios concretos sobre cómo la estructura político-social estaba condicionando la manifestación lingüística de una determinada comunidad de habla. La política más centralista de los borbones en los inicios del siglo XVIII motivaría una pérdida de poder progresiva de la iglesia en los asuntos lingüísticos, pues el destino de una evangelización en lenguas indígenas se vería truncado por la intervención de un gobierno más interesado en la difusión del castellano que en la transmisión de una doctrina. La prensa reflejaba este cambio a través de comentarios en favor de la política de los monarcas y la creación de una opinión en contra de las lenguas indígenas como medios de expansión de un saber ilustrado: se reseñaban gramáticas de castellano -y cada vez menos de lenguas indígenas-; se incitaba al 
aprendizaje de otras "lenguas vivas" como el inglés o francés; se hablaba de la creación de escuelas de primeras letras, en donde el castellano (en las materias de leer y escribir) ocupaba un lugar esencial; se relataba la importancia de que los indios hablaran español, o se exponían la razones de por qué los maestros de escuela ocupaban un papel esencial en la educación de una población casi analfabeta. Conforme transcurrían los años, la prensa periódica reflejaba los cambios de aire políticos con consecuencias claras sobre el castellano: en el periodo de insurgencia, con las Cortes de Cádiz como modelo legislativo, el castellano tomaría un impulso impredecible, originado, paradójicamente, por las políticas de igualdad generadas por las leyes, ya que el indio dejaba de ser un elemento marginal de la sociedad y pasaba a convertirse en un ciudadano más (recuperaba libertad, pero perdía sus prebendas como ente no libre). La prensa seguía informando con más detalle sobre los planes lingüísticos del nuevo Estado, después de que se consumó la Independencia: los criollos serían ahora los encargados de construir un nuevo régimen político, en donde el español serviría como elemento unificador y transmisor de ideas, frente a la heterogeneidad de lo vernáculo, que se guardaba en el rincón del patrimonio cultural. Desaparecen las escuelas para indios y se fomenta la apertura de colegios gratuitos - en la medida en la que el dinero lo permitía-. La prensa, en definitiva, se erigirá como instrumento para la generación de una opinión pública favorable a un castellano que debía estudiarse, también paradójicamente, con los principios normativos de la antigua metrópoli.

\section{REFERENCIAS BIBLIOGRÁFICAS}

\section{FUENTES PRIMARIAS}

Clamores de la fidelidad americana contra la opresión.1813-1814. Mérida: Oficina de P. y L. de D. F. Bates. En http://www.hndm.unam.mx/consulta/resultados/visualizar/558075 bd7d1e63c9fea1a1a3?resultado $=5 \&$ tipo $=$ publicacion\&intPagina $=0$ [Fecha de consulta: 9/12/2019].

Diario de México. 1805-1810. México: Fernández Jáuregui. En http://www.hndm.unam.mx/ consulta/resultados/visualizar/558075be $7 \mathrm{~d} 1 \mathrm{e}$ e63c9fea1a213?resultado=2\&tipo=publicac ion\&intPagina $=0$. [Fecha de consulta: 23/11/2019].

El Farol. Periódico semanario de la Puebla de los Ángeles. 1821-1822. Puebla de los Ángeles: Imprenta liberal de Moreno Hermanos. En http://www.hndm.unam.mx/consulta/ publicacion/visualizar/558075be7d1e63c9fea1a27f?anio=1821\&mes=11\&dia=11\&tipo= publicacion [Fecha de consulta: 14/12/2019]. 
El Invitador. 1826-1827. Puebla: Imprenta de Moreno Hermanos. En http://www.hndm.unam. $\mathrm{mx} /$ consulta/resultados/visualizar/558075be7d1e63c9fea1a30d?resultado=18\&tipo=pub licacion\&intPagina $=0$ [Fecha de consulta: 12/12/2019].

El Nivel. 1825. Guadalajara: Imprenta del C. Urbano Sanromán. En http://www.hndm.unam. $\mathrm{mx} /$ consulta/resultados/visualizar/558075be7d1e63c9fea1a380?resultado=16\&tipo=pub licacion\&intPagina $=0$ [Fecha de lectura: 07/01/2020].

El Sol. 1824-1832. México: Imprenta Martín Rivera. En http://www.hndm.unam.mx/consulta/ resultados/visualizar/558075bf7d1e63c9feala446?resultado=13\&tipo=publicacion\&intP agina $=0$ [Fecha de consulta: 25/11/2019].

Fanal del Imperio Mexicano. 1822. México: L.L.H.H. Morán. En http://www.hndm.unam. $\mathrm{mx} /$ consulta/resultados/visualizar/558075be7d1e63c9fea1a27a?resultado=7\&tipo=publ icacion\&intPagina $=0$ [Fecha de consulta: $01 / 11 / 2019]$

Gaceta Imperial de México. 1821-1823. México: Alejandro Valdés. En http://www.hndm. unam.mx/consulta/resultados/visualizar/558075be7d1e63c9fea1a2a8? resultado=5\&tip $\mathrm{o}=$ publicacion\&intPagina $=0$ [Fecha de consulta: $15 / 10 / 2019]$.

Gaceta de México y noticias de Nueva España. 1722-1739. México: Castrorena Ursúa y Goyeneche/Ladrón de Guevara. En http://www.hndm.unam.mx/consulta/busqueda/ buscarPorRangoDeFecha?rango=1722-1799\&id=1 [Fecha de consulta: 07/10/2019].

Gazeta de México. 1784-1809. México: Valdés y Murguía. En http://www.hndm.unam.mx/ consulta/busqueda/buscarPorRangoDeFecha?rango=1722-1799\&id=1 [Fecha de consulta: 11/11/2019].

Gazeta del Gobierno de México. 1810-1821. México: Imprenta de Arizpe. http://www.hndm. unam.mx/consulta/resultados/visualizar/558075be7d1e63c9fea1a2a1?resultado=2\&tipo $=$ publicacion\&intPagina $=0$ [Fecha de consulta: 20/01/2020].

Iris de Jalisco. 1823-1825. México: Imprenta de Sanromán. En: http://www.hndm.unam.mx/ consulta/resultados/visualizar $/ 558075 \mathrm{be} 7 \mathrm{~d} 1 \mathrm{e} 63 \mathrm{c} 9 \mathrm{fea} 1 \mathrm{a} 30 \mathrm{e}$ ?resultado=12\&tipo=publica cion\&intPagina $=0$ [Fecha de consulta: 12/12/2019].

La Águila mexicana: periódico cotidiano, politico y literario. 1823-1827. México: Germán Nicolás Prisette. En http://www.hndm.unam.mx/consulta/resultados/visualizar/558075b d7d1e63c9fea1a0f3?resultado $=11 \&$ tipo $=$ publicacion\&intPagina $=0$ [Fecha de consulta: 17/11/2019].

La Sabatina Universal. Periódico político y literario. 1822. México: Doña Herculana del Villar y Socios. En: http://www.hndm.unam.mx/consulta/resultados/visualizar/558075bf7d1e63c 9 fea1a42d?resultado=8\&tipo=publicacion\&intPagina $=0$ [Fecha de consulta: 18/12/2019].

Semanario económico de México. 1810. México: Casa de Arizpe. En: http://www.hndm.unam. $\mathrm{mx} /$ consulta/resultados/visualizar/558075bf7d1e63c9fea1a43b?resultado=3\&tipo=publi cacion\&intPagina $=0$ [Fecha de consulta: 03/11/2019].

Semanario político y literario. 1821. México: Imprenta de Valdés. En: http://www.hndm. unam.mx/consulta/resultados/visualizar/558075bf7d1e63c9fea1a43e?resultado=4\&tipo $=$ publicacion\&intPagina $=0$

\section{FUENTES SECUNDARIAS}

Aguirre Beltrán, Gonzalo. 1972. Educación y nacionalidad. Anuario Antropológico 3: 435-444.

1993. Lenguas vernáculas: su uso y desuso en la enseñanza: La experiencia de México. México: Fondo de Cultura Económica.

Amorós Negre, Carla. 2008. Diferentes perspectivas en torno a la planificación lingüística". En Inés Olza Moreno, Manuel Casado Velarde y Ramón González Ruiz (eds.). Actas 
del XXXVII Simposio Internacional de la Sociedad Española de Lingüística, pp. 17-29. Pamplona: Servicio de Publicaciones de la Universidad de Navarra.

Anderson, Benedict. 1983. Imagined communities. Reflections on the origin and Spread of Nationalism. Londres: Verso.

Angenot, Marc. 1982. La parole pamphlétaire. Contribution à la typologie des discours modernes. Paris: Payot.

Arredondo López, María Adelina. 2011. Educación y diversidad cultural: políticas, prácticas educativas e indígenas en Chihuahua durante la primera mitad del siglo XIX. En María de Lourdes Alvarado y Rosalina Ríos Zúñiga (eds.). Grupos marginados de la educación (siglos XIX Y XX), pp. 375-395. Ciudad de México: Bonilla Artigas Editores.

BÁEz Pinal, Gloria Estela. 2009. Del catecismo a los libros de texto gratuitos. Un panorama histórico de la enseñanza del español en la escuela primaria. En José Moreno de Alba, Gloria Estela Báez Pinal, Elizabeth Luna Traill y Tatiana Sule Fernández (eds.). Historia y presente de la enseñanza en México, pp. 13-186. México: UNAM.

Bein, Roberto. 2013. Políticas lingüísticas nacionales y de integración regional en América Latina. En Elivira Narvaja de Arnoux, y Susana Nothstein (eds.). Temas de glotopolítica. Integración regional sudamericana y panhispanismo, pp. 75-91. Buenos Aires: Biblos.

Bein, Roberto y J. Born. (eds.). 2001. Políticas lingüísticas. Norma e identidad. Buenos Aires: Universidad de Buenos Aires.

Blommaert, Jan. 1999. Language Ideological Debates. Berlín: Walter de Gruyter.

Bourdieu, Pierre. 2001. Langage et pouvoir symbolique. Paris: Seuil/Points.

Brice, Shirley. 1972. La política del lenguaje en México: de la colonia a la nación. México: Instituto Nacional Indigenista.

Buisán, ANDRÉs. 2013. Representaciones de la lengua española: del panhispanismo a la Comunidad Iberoamericana de Naciones. En Elvira Narvaja de Arnoux y Susana Nothstein (eds.). Temas de glotopolítica. Integración regional sudamericana y panhispanismo, pp. 1-25. Buenos Aires: Biblos.

Cameron, Deborah. 1995. Verbal Hygiene. The Politics of Language. Londres/Nueva York: Routledge.

Caso, Alfonso, Silvio Zavala, José Miranda y Moisés González Navarro. 1973. La política indigenista en México. Métodos y resultados. México: Instituto Nacional Indigenista y Secretaría de Educación Pública.

Christian, Donna. 1992. La planificación de las lenguas desde el punto de vista de la lingüística". En F. Newmeyer (ed.). Language Planning: The View from Linguistics, pp. 232-252. Madrid: Visor.

Cooper, Robert L. 1997. Language Planning and Social Change. Cambridge: Cambridge University Press.

Ennis, Juan Antonio y Guillermo Toscano y García. 2019. La lengua en disputa: los debates en la prensa escrita y una historia de la lengua para el siglo XXI. Olivar 29/19: 1-10.

Fairclough, Norman. 2001. Language and power. London: Longman.

Ferguson, Charles. 1996. Conventional Conventionalization. En T. Huebner (ed.). Sociolinguistic Perspectives. Papers on Language in Society 1959-1994, pp. 261-323. Oxford: Oxford University.

Fernández de Lizardi, José Joaquín. 1962. El pensador mexicano. México: UNAM.

Fishman, Joshua A. 1974. Advances in Language Planning. The Hague: Mouton.

Flores Rodríguez, María Eugenia Xilonetl. 2012. Juan de Dios Rodríguez Puebla: en defensa de la instrucción para los indios. En Margarita Moreno-Bonett y Rosa María Álvarez de Lara, El Estado laico y los derechos humanos en México: 1810-1820, pp. 409-420. México: UNAM. 
Garone Gravier, Marina. 2014. Historia de la tipografia colonial para lenguas indígenas. México: Centro de Investigación y Estudios Superiores en Antropología Social.

Garza Cuarón, Beatriz. 1991. Políticas lingüísticas hacia la Nueva España en el siglo XVIII. Nueva Revista de Filología Hispánica 34/2: 689-706.

Gómez AsENCIO, José Jesús. 2009. De 'gramática para americanos' a 'gramática de todos': el caso de Bello (1847). Revista argentina de historiografia lingüística 1: 1-18.

González Luna, Ana María. 2012. La política lingüística en México entre Independencia y Revolución (1810-1919). En Patrizia Botta y Sara Pastor (coords.). Rumbos del hispanismo en el umbral del Cincuentenario de la AIH, vol. 8, pp. 91-101. Milán: Bagatto Libri.

Gorman, Thomas. 1973. Language allocation and language planning. En J. Rubin y R. Shuy (eds.). Language Planning: Current Issues and Research, pp. 72-82. Washington DC: Georgetown University Press.

Hall, Robert Anderson. 1950. Leave Your Language Alone. New York: Ithaca.

Haugen, Einar. 1959. Planning for a Standar Language in Modern Norway. Anthropological Linguistics 1/3: 8-21.

Heath, Shirley Brice (1972). La política del lenguaje en México: de la colonia a la nación. México: Instituto Nacional Indigenista.

Heller, Monica. 2010. The Commodification of Language. Annual Review of Anthropology 39: 101-114.

JERNUDD, BJÖRN H. y JiRI V. NeUSTUPNý. 1987. Language Planning for Whom”. En I. Laforge (ed.). Proceedings of the International Colloquium on Language Planning, pp. 71-84. Québec: Université Laval.

KLeIN, Wolf. 1999. Regeln verordnen; Neue Forschungen zum Problem der Sprachnormen. Frankfurter Allgemeine Zeitung 01.09.1999.

Kloss, Heinz. 1969. Research Possibilities on Group Bilingualism: a Report. Québec: International Center for Research on Bilingualism.

Latham, Sean y Robert Scholes. 2006. The Rise of Periodical Studies. PMLA 121.2: 517-531

Lemus, José Miguel. 2020. De la patria criolla a la nación mexicana: surgimiento y articulación del nacionalismo en la prensa novohispana del siglo XVIII, en su contexto, Madrid: Pliegos.

LODARES MARRODÁN, JUAN RAMÓN. 2006. La contradictoria legislación lingüística americana (1500-1770), En José Luis Girón Alconchel y José Jesús Bustos Tovar, Actas del VI Congreso Internacional de Historia de la Lengua Española, pp. 2235-2242. Madrid: Arco Libros.

MacKenzie, Donald, Peter McDonald y Michael Suarez. 2002. Making Meaning: "Printers of the Mind" and Other Essays. Massachusetts: Massachusetts University Press.

Magallanes Delgado, María del Refugio. 2011. Pobres, vagos e instrucción para el trabajo. Del "taller" a la escuela de artes y oficios en Zacatecas (1775-1862). En María de Lourdes Alvarado y Rosalina Ríos Zúñiga, Grupos marginados de la educación (siglos $X I X Y X X)$, pp. 79-112. Ciudad de México: Bonilla Artigas Editores.

Miller, George A. 1950. Language Engineering. Journal of the Acoustical Society of America 22/6: 720-725.

Milroy, James y Lesley Milroy. 1999. Authority in Language: Investigating Standard English. Oxford: Routledge.

Moreno Fernández, Francisco. 2008. Principios de sociolingüistica y sociología del lenguaje. Barcelona: Ariel.

Narvaja de Arnoux, Elvira. 2000. La Glotopolitica: Transformaciones de un campo disciplinario. Lenguaje: Teorías y prácticas. Buenos Aires: Gobierno de la Ciudad de Buenos Aires. 
2013b. En torno a la Nueva gramática de la lengua española (Real Academia Española y Asociación de Academias de la Lengua Española). En Elvira Arnoux de Narvaja y Susana Nothstein (eds.). Temas de glotopolítica, pp. 245-270. Buenos Aires: Biblos.

Narvaja de Arnoux, Elvira y Roberto Bein. (eds.). 2010. La regulación política de las prácticas lingüisticas. Buenos Aires: Eudeba.

(eds.). 2015. Política lingüística y enseñanza de lenguas. Buenos Aires: Biblos.

Narvaja de Arnoux, Elvira y Susana Nothstein. 2013a. Temas de glotopolítica: integración regional sudamericana y panhispanismo. Buenos Aires: Biblos.

Neustupný, JiRi. V. 1970. Basic types of treatment of language problems. Linguistic Communications 1: 77-98.

Niro, Mateo. 2013. Bartolomé Melià, la retórica jesuita y la reducción de la lengua guaraní. En Elvira Narvaja de Arnoux y Susana Nothstein (eds.). Temas de glotopolítica. Integración regional sudamericana y panhispanismo, pp. 51-74. Buenos Aires: Biblos.

Noss, RicharD. 1967. Higher Education and Development in South-East Asia. Language Policy and Higher Education. Paris: International Association of Universities.

Ramírez Castañeda, Elisa. 2006. La educación indígena en México. México: UNAM.

Rivas ZANCARRón, MANUEL. 2017a. Acercamiento metodológico al estudio de las actitudes lingüísticas ante el sistema gráfico en la prensa española del siglo XVIII. En José María Santos Rovira (ed.). Variación lingüistica e identidad en el mundo hispanohablante, pp. 11-29. Lugo: AXAC.

2017b. Actitudes ante la lengua en el pensamiento gramatical del siglo XVIII. Algunas consideraciones metodológicas en el acceso al objeto de estudio, Boletín de la Sociedad Española de Historiografía Lingüística 11: 167-191.

2018a. Barbarie y pureza de la palabra: el concepto de neologismo en José Joaquín de Mora. En Alberto Romero Ferrer (ed.). José Joaquín de Mora o la inconstancia. Periodismo, política y literatura, pp. 153-176. Madrid: Visor Libros.

2018b. La forma de los tipos gráficos como instrumento para la expresión de actitudes lingüísticas en la prensa costarricense del siglo XIX. Boletín de Filología 53, 1: 237-265.

2019a. Actitudes lingüísticas implícitas y explícitas en la composición de cartas privadas en América y España durante los siglos XVIII y XIX. Boletín de la Real Academia Española 94: 835-884.

2019b. La figura del gramático como agente del cambio lingüístico: evolución de sus actitudes ante la lengua en España y América (ss. XVIII y XIX). Neuphilologische Mitteilungen 120, 1: 171-206.

2020a. Creencias y actitudes ante el sistema gráfico durante la primera mitad del siglo XIX chileno. En Manuel Rivas Zancarrón, y Victoriano Gaviño Rodríguez (eds.). Creencias y actitudes ante la lengua en España y América (siglos XVIII y XIX), pp. 341386. Madrid: Iberoamericana Vervuert.

2020b. Escritura impresa vs. escritura manuscrita en la Costa Rica del siglo XIX. Actitudes y creencias en torno a la manifestación escrita. Boletín de Filología 55, 2: 465-502.

2020c. Gramática y debate político en el Chile de la primera mitad del siglo XIX. Actitudes explícitas ante la lengua. Boletín de la Sociedad Española de Historiografía Lingüística 14: 37-63.

Rizzo, María Florencia. 2013. Antecedentes de la política lingüística panhispánica: los congresos de la lengua española. En Elvira Narvaja de Arnoux y Susana Nothstein (eds.). Temas de glotopolítica. Integración regional sudamericana y panhispanismo, pp. 191220. Buenos Aires: Biblos.

Roca, María del Pilar. 2013. Las insatisfacciones y representaciones del uso ante la ortografía del castellano. En Elvira Narvaja de Arnoux y Susana Nothstein (eds.). Temas 
de glotopolítica: Integración regional sudamericana y panhispanismo, pp. 221-244. Buenos Aires: Biblos.

Rojas, Darío. 2015. Ideologías y actitudes lingüisticas en el Chile hispanohablante de la segunda mitad del siglo XIX. Tesis doctoral. Valladolid: Universidad de Valladolid.

Rojas, Darío y TANia Avilés. 2014a. Diccionario y estandarización lingüística en Hispanoamérica: la visión de Ramón Sotomayor Valdés (1866), Estudios Filológicos 53: $109-121$.

2014b. Ideologías lingüísticas en la fraseología del español de Chile: dos momentos, una misma concepción del lenguaje. Onomázein 29: 64-77.

ROSENBLAT, ÁNGEL. 1984. El criterio de corrección lingüística: unidad o pluralidad de normas en el castellano de España y América. Estudios sobre el español de América, pp. 311-337. Caracas: Monte Ávila Editores.

Rotaetxe Amusategui, Karmele. 1990. Sociolingüística. Madrid: Síntesis.

Rubin, JoAn. 1975. Evaluation and Language Planning. En J. Rubin y B. H. Jernudd (eds.). Can Language Be Planned?: Sociolinguistic Theory and Practice for Developing Nations, pp. 217-252. Honolulu: The University Press of Hawaii.

Rubin, JoAn y Björn H. Jernudd (eds.). 1975. Can Language Be Planned?: Sociolinguistic Theory and Practice for Developing Nations. Honolulu: The University Press of Hawaii.

Staples, AnNe. 2011. Una educación en desventaja. El México indígena (1821-1854). En María de Lourdes Alvarado y Rosalina Ríos Zúñiga, Grupos marginados de la educación (siglos XIX Y XX), pp. 335-372. Ciudad de México: Bonilla Artigas Editores.

Tanck De Estrada, Dorothy. 1989. Castellanización, política y escuelas de indios en el arzobispado de México a mediados del siglo XVIII. Historia Mexicana, 38/4, México, 701-741.

2000. Pueblos de indios y educación en el México colonial, 1750-1821. Ciudad de México: El Colegio de México.

Tauli, Valter. 1974. El planeamiento del lenguaje. En O. Uribe Villegas (ed.). La sociolingüística actual, pp. 246-267. México: UNAM.

Torrejón, Alfredo. 1989. Andrés Bello, Domingo Faustino Sarmiento y el castellano culto de Chile. Thesaurus 44/3: 534-558.

VALLE, José Del. 2007. Glotopolítica, ideología y discurso: Categorías para el estatuto simbólico del español. En José del Valle (ed.). La lengua, ¿una patria común? Ideas e ideologías del español, pp. 13-30. Madrid: Iberoamericana.

Varela, Lía. 2013. Para una implementación de la ley de portugués. En Elvira Narvaja de Arnoux y Susana Nothstein (eds.). Temas de glotopolítica. Integración regional sudamericana y panhispanismo, pp.121-150. Buenos Aires: Biblos.

Velasco Ceballos. 1945. La alfabetización en la Nueva España. México: Secretaría de Educación Pública.

WoOlard, Kathryn 2012. Las ideologías lingüísticas como campo de investigación. En B. Schieffelin, K. Woolard y P. Kroskrity (eds.). Idologías lingüísticas. Práctica y teoría, pp. 19-69. Madrid: Catarata. 